\title{
Geoquímica e geocronologia U-Pb e Sm-Nd dos ortognaisses da região de Pontalina (GO), Brasil
}

\section{Geochemistry and geochonology $\mathrm{U}-\mathrm{Pb}$ and $\mathrm{Sm} / \mathrm{Nd}$ data of the orthogneiss from Pontalina region (GO), Brazil}

\author{
Guillermo Rafael Beltran Navarro ${ }^{1 *}$, Antenor Zanardo ${ }^{2}$, \\ Fabiano Tomazini da Conceição ${ }^{3}$, Cibele Carolina Montibeller ${ }^{4}$
}

\begin{abstract}
RESUMO: Na regiáo de Pontalina (GO) afloram ortognaisses de composição tonalítica a granodiorítica e caracteríticas calcioalcalinas, metaluminosas a peraluminosas. Exibem anomalias negativas de $\mathrm{Nb}, \mathrm{Ta}, \mathrm{P} \mathrm{e} \mathrm{Ti}$ em relaçáo a elementos terras raras (ETR) e a elementos litófilos e baixos conteúdos em elementos como $\mathrm{Nb}, \mathrm{Ta}, \mathrm{Y}$ e $\mathrm{Yb}$, similar às rochas formadas em ambientes de subducção. Dados geocronológicos U-Pb mostram que a idade de cristalização desses ortognaisses é neoproterozoica $(681,5 \pm 7,7 \mathrm{Ma})$. Os dados isotópicos $\varepsilon_{\mathrm{v}}(\mathrm{T})$ são fracamente negativos a positivos $(+3,2$ e $-0,1)$, com idades modelo $\mathrm{T}_{\mathrm{DM}} \mathrm{de} \sim 1,2 \mathrm{Ga}$. Em conjunto, os dados geoquímicos e isotópicos obtidos sugerem que o protolito desses ortognaisses são magmas juvenis, com idade neoproterozoica, formados em um sistema de arco de ilha. Este evento foi desenvolvido, provavelmente, durante um evento de acresçáo crustal na borda oeste do Cráton do São Francisco entre 700 e 600 Ma.
\end{abstract}

PALAVRAS-CHAVE: geoquímica; geocronologia; ortognaisse; arco magmático de Goiás.

\begin{abstract}
Orthogneisses of tonalitic to granodioritic composition with calc-alkaline, metaluminous to peraluminous characteristics crop out at the region of Pontalina. The orthogneisses exhibit negative anomalies of $N b, T a, P$ and Ti relative to rare earth elements (REE) and litophile elements, besides low contents of $N b, T a, Y$ and $Y b$, similar to the rocks formed in subduction environments. U-Pb geochronological data show a neoproterozoic $(681.5 \pm 7.7 \mathrm{Ma})$ crystallization for the orthogneisses. The $\mathrm{Nd}$ isotope data yielded weakly negative to positive $\varepsilon_{N d}(T)\left(+3.2\right.$ up to -0.1), with $T_{D M}$ model ages of $-1.2 \mathrm{Ga}$. The combined geochemical and isotopic data suggest that the protolith of these orthogneisses are representative of neoproterozoic juvenile magmas, probably developed in an island arc system, generated during a ca.700 and $600 \mathrm{Ma}$ event of crustal accretion in the western edge of the Saa Francisco Craton.
\end{abstract}

KEYWORDS: geochemistry; geochronology; orthogneiss; Goiás magmatic arc.

\footnotetext{
${ }^{1}$ Programa de Pós-graduação em Geologia Regional, Instituto de Geociências e Ciências Exatas, Universidade Estadual Paulista “Júlio de Mesquita Filho” - UNESP, Rio Claro (SP), Brasil. E-mail: grbnavarro@yahoo.com.br

2Departamento de Petrologia e Metalogenia, Universidade Estadual Paulista “Júlio de Mesquita Filho” - UNESP, Rio Claro (SP), Brasil. E-mail: azanardo@rc.unesp.br ${ }^{3}$ Departamento de Planejamento Territorial e Geoprocessamento, Universidade Estadual Paulista "Júlio de Mesquita Filho" - UNESP, Rio Claro (SP), Brasil. E-mail: ftomazini@rc.unesp.br

${ }^{4}$ Aluna de Graduação no Curso de Geologia, Universidade Estadual Paulista “Júlio de Mesquita Filho” - UNESP, Rio Claro (SP), Brasil. E-mail: cibelegeologia@uol.com.br *Autor correspondente: Pós-doutorando junto ao programa de pós-graduação em Geologia Regional. Instituto de Geociências e Ciências Exatas (IGCE), Universidade Estadual Paulista "Júlio de Mesquita Filho" (UNESP). Endereço: Av. 24 A no 1515. Bairro: Bela Vista. Rio Claro. UF: São Paulo. CEP:13506-900. e-mail: grbnavarro@yahoo.com.br Manuscrito ID 21565. Recebido em: 23/05/2011. Aprovado em: 09/04/2013
} 


\section{INTRODUÇÃO}

A Faixa Brasília corresponde a um cinturão orogênico neoproterozoico resultante da convergência de três importantes blocos continentais, ou seja, o Cráton Amazônico a oeste, o Cráton do São Francisco a leste e o Bloco Paranapanema ao sul. Este cinturão orogênico estende-se por mais de $1.100 \mathrm{~km}$, desde o do sul de Minas Gerias, passando por toda extensão de Goiás e terminando no sul de Tocantins (Fig. 1). Seguindo a compartimentação proposta por Fuck (1990) e Fuck et al. (1994), a Faixa Brasília Meridional é dividida em Zona Externa e Zona Interna. A Zona Externa é composta por unidades metassedimentares pertencentes aos Grupos Paranoá e Canastra, pelas formações Vazante e Ibiá. A Zona Interna é constituída por unidades metassedimentares e vulcanogênicas associadas ao Grupo Araxá, terrenos ortognáissicos, sequências vulcanossedimentares neoproterozoicas, Arco Magmático de Goiás e rochas de alto grau do Complexo Granulítico AnápolisItauçu. A porção interna da Faixa Brasília, na porção SW-S de Goiás, é constituída pelo Complexo Anápolis-Itauçu e Associação Ortognáissica Migmatítica, Grupo Araxá e Arco Magmático de Goiás (Fig. 2).

$\mathrm{Na}$ porçấo SW-S de Goiás, o Grupo Araxá é dividido em duas unidades denominadas de A e B (Lacerda Filho, Rezende \& Silva 1999). A Unidade A é formada por metassedimentos plataformais do tipo marinho raso, constituídos por muscovita-clorita xistos, às vezes com cloritoide, biotita-muscovita-quartzo xistos, granada-muscovita-clorita xistos, clorita-quartzo xistos, grafita xistos, sericita quartzitos e hematita-sericita quartzitos. Sequências metavulcanossedimentares (sequências Maratá e Rio Veríssimo) ocorrem associadas aos metassedimentos da Unidade $\mathrm{A}$, na região de Ipameri-Catalão. A Unidade B é constituída por uma

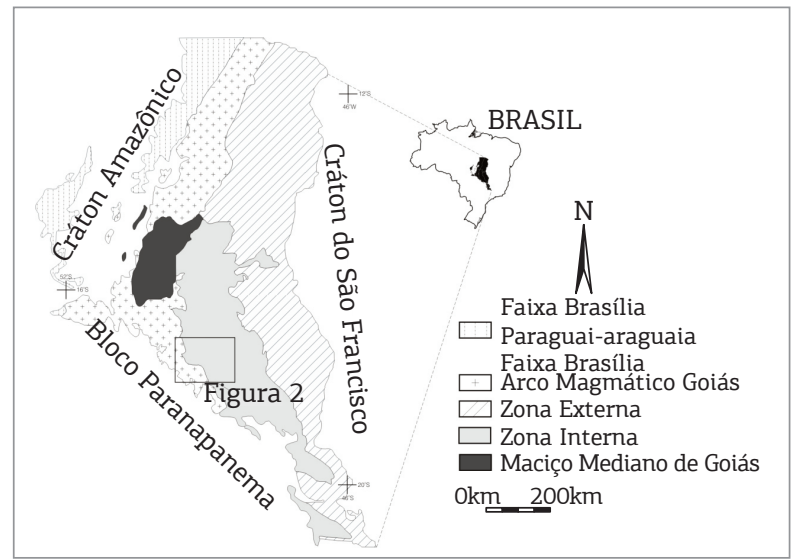

Figura 1. Mapa esquemático da porção oriental da Província Tocantins mostrando a localização da área de estudo (modificado de Fuck et al. 1994). sequência pelítica marinha formada por calci-clorita-biotita xisto feldspáticos, calci-granada-biotita-quartzo xistos feldspáticos, granada-clorita xistos, hornblenda-granada xistos feldspáticos, grafita xistos, lentes de metacalcários, quartzitos micáceos e, subordinadamente, lentes de anfibolitos.

A ocorrência de lentes de rochas metaultramáficas (serpentinitos, talco xistos e clorita xistos) localmente com cromititos associados, intercalados nos metassedimentos do Grupo Araxá, com características geoquímicas e texturais/estruturais de complexos do tipo alpino, é usada para inferir o caráter de mélange ofiolítica para o Grupo Araxá (Drake Jr. 1980, Strieder \& Nilson 1992). Anfibolitos com características geoquímicas e isotópicas de basaltos oceânicos (do tipo E-MORB) também ocorrem, associados aos metassedimentos do Grupo Araxá, e são interpretados como fragmentos de crosta oceânica (Seer et al. 2001).

O Complexo Anápolis-Itauçu é composto por:

- granulitos ortoderivados que incluem corpos máfico-ultramáficos acamadados e de composição tonalítica a granodiorítica;

- granulitos aluminosos, leptinitos e granada gnaisses associados com mármores, rochas calciossilicáticas, quartzitos e granulitos máficos finos;

- estreitas faixas de sequências vulcanossedimentares compostas de anfibolitos, micaxistos, rochas metavulcânicas félsicas, metacherts e formaçóes ferríferas;

- intrusóes graníticas (Marini et al. 1984, Pimentel et al. 2000, Pimentel, Jost \& Fuck 2004).

A Associação Ortognaissica Migmatítica é constituída por metatonalitos, metatonalitos aluminosos, metagranitos, metagranodioritos e migmatitos, que gradam lateralmente para gnaisses quartzo-feldspáticos migmatizados. Esta gradação sugere fusão parcial de intensidade diferenciada a partir dos gnaisses paraderivados pertencentes ao Complexo Granulítico Anápolis-Itauçu (Oliveira 1994).

O Arco Magmático de Goiás é representado por ortognaisses com faixas de rochas metassedimentares e metavulcânicas, que são interpretadas como parte de crosta juvenil com assinatura geoquímica e isotópica de arcos magmáticos intraoceânicos a cordilheiranos, formados durante ciclo orogênico Brasiliano (Pimentel \& Fuck 1991, 1992, Pimentel et al. 2000, Valeriano et al. 2004). Ao Arco Magmático de Goiás associam-se corpos graníticos (Serra Negra, Serra do Irã, Caiapó, Iporá, Israelândia, Serra do Impertinente, Fazenda Nova, Novo Brasil) e máfico-ultramáficos (complexos Americano do Brasil e Anicuns-Santa Barbará, diorito Córrego do Lajeado) tardi- a pós- cinemáticos, resultantes de magmatismo bimodal, relacionados ao último estágio colisional da Faixa Brasília (Pimentel et al. 2000, Valeriano et al. 2004). 


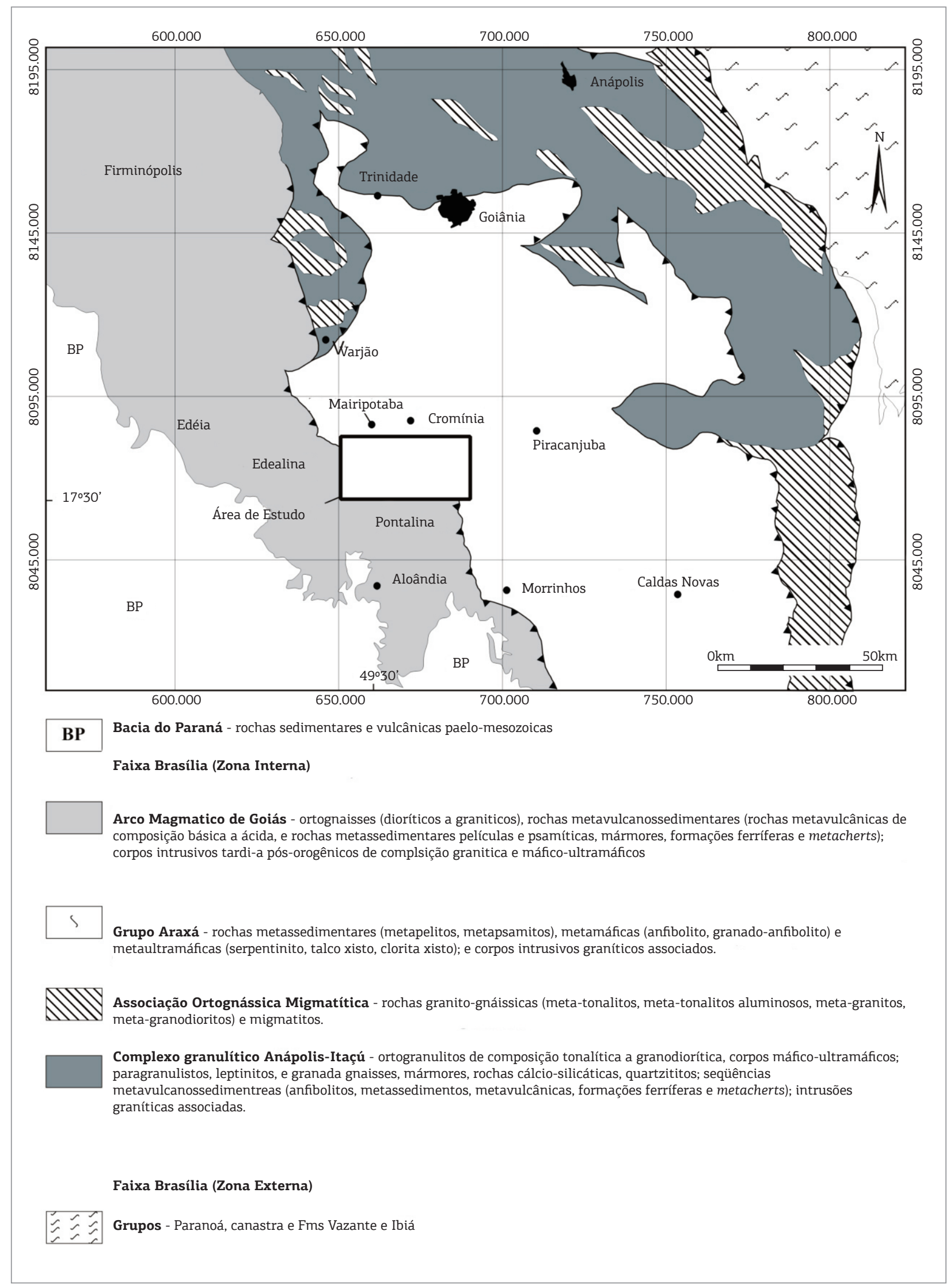

Figura 2. Mapa geológico esquemático regional mostrando a localização da área de estudo (Modificado de Lacerda Filho, Rezende \& Silva 1999). 
$\mathrm{Na}$ região de Pontalina (GO), os terrenos gnáissicos associados ao Arco Magmático de Goiás são agrupados sob a denominação informal de Terrenos GnáissicoMetassedimentares, que são subdivididos em duas unidades geológicas: Unidade Gnáissica e Unidade Metassedimentar (Fig. 3). Na Porção W da unidade Gnáissica (a NW de Pontalina) esta unidade é constituída por ortognaisses, os quais ainda não apresenta nenhum estudo detalhado que aborde seus aspectos geológicos, geoquímicos e geocronológicos. Assim, o objetivo deste trabalho foi a caracterização geológica, geoquímica e geocronológica do Ortognaisse Pontalina, fato que possibilita um melhor entendimento desta regiāo de Goiás relacionada à Faixa Brasília.

\section{GEOLOGIA LOCAL}

A Unidade Gnáissica consiste em uma faixa de gnaisses variados que incluem muscovita gnaisses, biotita-muscovita gnaisses, hornblenda gnaisses, hornblenda-biotita gnaisses ocelares ou não, geralmente quartzosos e ricos em epídoto, e com grau variado de milonitização. São frequentes intercalaçóes de rochas metamáficas/metabásicas (anfibolitos e anfibólio xisto/fels) e sílico-aluminosas representadas principalmente por muscovita xistos e muscovitaquartzo xistos. Quimicamente, os gnaisses desta unidade apresentam composição cálcica a calcioalcalina, metaluminosa a peraluminosa, baixos teores em álcalis, enriquecimento em $\mathrm{Ba}, \mathrm{Sr}, \mathrm{K}, \mathrm{Rb}$ em relação a $\mathrm{Nb}, \mathrm{Y}, \mathrm{Zr}$ e elementos terras raras (ETR) e anomalias negativas de Ti e $\mathrm{Nb}$, semelhantes à composição de magmas gerados em ambientes de arcos magmáticos (Navarro \& Zanardo 2007a). Idades modelo $\mathrm{T}_{\mathrm{DM}}$ de gnaisses desta unidade variam entre 0,90 a 1,26 Ga, com composiçôes isotópicas ${ }^{147} \mathrm{Sm} /{ }^{144} \mathrm{Nd}$ e ${ }^{143} \mathrm{Nd} /{ }^{144} \mathrm{Nd}$ variando entre 0,1079 - 0,1487 e 0,512173 0,512600, respectivamente (Navarro \& Zanardo 2007a).

A Unidade Metassedimentar é constituída essencialmente por muscovita xistos, muscovita-quartzo xistos e quartzitos, intercalados por muscovita gnaisses e biotitamuscovita gnaisses, geralmente com forte muscovitização e ricos em epídoto, além de rochas metamáficas/metabásicas. Os gnaisses desta unidade são orto ou paraderivados

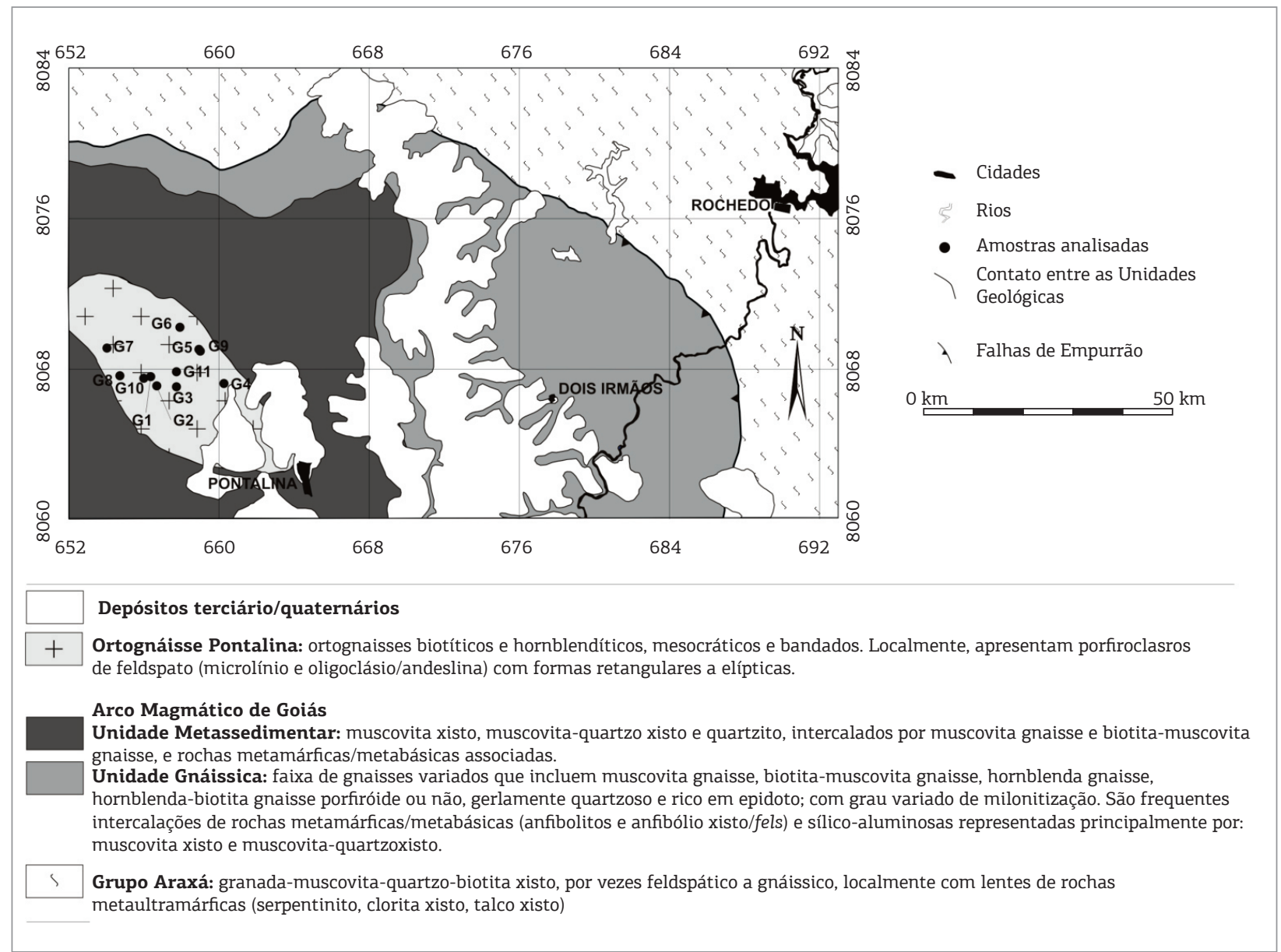

Figura 3. Mapa geológico esquemático da região de Pontalina (GO) mostrando a localização das amostras analisadas. 
e apresentam composição predominantemente peraluminosa, afinidade calcioalcalina e norma predominantemente granítica. Exibem grande variação no conteúdo de elementos maiores e traços, com teores baixos a moderados de $\mathrm{Y}$ e $\mathrm{Nb}$ e alto de $\mathrm{Ba}$, Sr e Rb, semelhante aos gnaisses da Unidade Gnáissica (Navarro \& Zanardo 2007b).

As rochas metamáficas/metabásicas (anfibolitos, granada anfibolitos, granada-anfibólio xistos e anfibólio xistos) ocorrem na forma de corpos lenticulares, de espessuras decimétricas a decamétricas com extensões métricas a hectométricas. Estes são orientados paralelamente ao bandamento das rochas encaixantes, tanto na Sequência Gnáissica como na Metassedimentar, sendo bem menos frequentes nesta última unidade. São de origem ortoderivada e, quimicamente, possuem natureza básica, predominando composiçóes de basaltos e basaltos andesíticos de afinidade toleítica subalcalina a alcalina, com características geoquímicas semelhantes a basaltos oceânicos, principalmente do tipo E-MORB e de basaltos de arco (Navarro \& Zanardo 2006, Navarro, Zanardo \& Simóes 2007). Dados isotópicos $\mathrm{Sm}-\mathrm{Nd}$ de anfibolitos da regiāo apresentam idades modelo $\mathrm{T}_{\mathrm{DM}}$ entre 1,0 a 1,23 e composiçôes isotópicas ${ }^{147} \mathrm{Sm} /{ }^{144} \mathrm{Nd}$ variando entre $0,106-0,122$ e ${ }^{143} \mathrm{Nd} /{ }^{144} \mathrm{Nd}$ variando entre $0,512164-0,512445$ (Navarro \& Zanardo 2006, Navarro, Zanardo \& Simóes 2007).

Rochas metaultramáficas (clorita xisto, talco xisto e serpentinito) ocorrem nas duas sequências, sendo a ocorrência mais importante o Morro Dois Irmãos, localizado a E de Pontalina.

\section{Geologia estrutural e metamorfismo}

A principal estrutura observada nas rochas da região é uma foliação principal (Sn), de caráter regional, normalmente paralela, a bandamento composicional. Esta foi denominada de foliação Sn e é caracterizada pela orientação de filossilicatos (muscovita, biotita, serpentina, talco, clorita, etc.), grãos de quartzo alongados, prismas de epídoto, cristais de hornblenda orientados, trilhas de minerais opacos e agregados policristalinos lenticulares a fusiformes. Essa trama define uma xistosidade, com grau variável de desenvolvimento, feiçôes blastomiloníticas de direção geral N-S a NNW/SSE com baixo a médio ângulo de mergulho para W. No extremo norte da área esta foliação está disposta, aproximadamente, na direção E-W, com mergulho baixo a médio para S. Localmente ocorre uma xistosidade bem desenvolvida denominada de foliação $S n-1$, paralela a um bandamento composicional milimétrico a métrico constituído por variaçôes de porçôes lepidoblásticas e granoblásticas (em metassedimentos, rochas metaultramáficas e gnaisses), por porçôes granoblásticas e nematoblásticas em rochas metamáficas e pela intercalação, centimétrica a métrica de diferentes litotipos paralelos. Esta xistosidade $S n-1$ é dobrada e transposta pela foliação principal (Sn). Associado a Sn há uma lineaçáo mineral e/ou de estiramento que apresenta baixo ângulo de mergulho para W e possui caimento geral para W (N76E/09SW). Os indicadores cinemáticos apontam sistematicamente transporte de topo para E.

As paragêneses e associaçóes minerais presentes nas rochas da região, relacionadas ao pico do metamorfismo são típicas da fácies anfibolito. Nas rochas encaixantes (gnaisses e metassedimentos), as associações minerais relacionadas ao ápice metamórfico são marcadas pela presença de plagioclásio + feldspato potássico + biotita, plagioclásio + biotita + hornblenda, localmente com granada e rutilo associados e hornblenda + granada + plagioclásio + (estaurolita) + (cianita) em metassedimento pelítico a psamíticos, além de quartzo e muscovita presentes em todas as paragêneses. Essas associaçóes indicam que o ápice metamórfico ocorreu no campo de estabilidade da cianita em regime de pressão compatível ou superior ao barroviano.

Nas rochas metaultramáficas no geral, observa-se apenas o produto da destruição total da mineralogia e das texturas primárias, restando apenas associaçôes minerais e paragêneses típicas da fácies xisto verde/anfibolito inferior $\left(<550^{\circ} \mathrm{C}\right.$ e $\left.5,5 \mathrm{kbar}\right)$, constituídas por associações do tipo serpentina + talco, talco + clorita, normalmente com magnetita e carbonato. Raramente, são observados restos de olivina e pseudomorfos (olivina e/ou piroxênio), com tramas sugestivas de reequilíbrio metamórfico de fácies anfibolito.

Nas rochas metamáficas, as assembleias metamórficas são representadas pelas associações anfibólio + plagioclásio $+($ quartzo $)+($ rutilo $)+($ ilmenita $)$ e granada + anfibólio + plagioclásio + (quartzo $)+($ rutilo $)+($ ilmenita $)$, ocorrendo muscovita e epídoto associados em algumas amostras. Estas associaçôes revelam que o ápice metamórfico atingiu condiçôes de fácies anfibolito médio a superior, na zona da cianita. Aspectos texturais e microestruturais indicam que estas associaçôes foram geradas no estágio inicial do desenvolvimento da foliação principal (Sn) ou mesmo antes (Sn-1).

As associaçóes minerais e os cálculos termobarométricos (para as associaçóes envolvendo anfibólio cálcico + plagioclásio e plagioclásio + granada + anfibólio cálcico) mostram que, na região, o ápice metamórfico ocorreu na fácies anfibolito médio a superior e atingiu temperaturas pouco superiores a $700^{\circ} \mathrm{C}$ (não ultrapassando $775^{\circ} \mathrm{C}$ ), em condições de média pressão ( $\sim 10 \mathrm{kbar})$, no campo de estabilidade da cianita (Navarro et al. 2011).

\section{O ORTOGNAISSE PONTALINA}

A noroeste da cidade de Pontalina, a Unidade Gnáissica é constituída por ortognaisses biotíticos e hornblendíticos, 
mesocráticos com bandamento composicional, informalmente denominados de ortognaisse Pontalina. Localmente, apresentam porfiroclastos de feldspato (microclínio e oligoclásio/andesina), com formas retangulares a elípticas, orientadas segundo a foliação principal. São granoblásticos a lepidoblásticos, possuem bandamento composicional, granulação média a grossa e foliação marcante, com porções miloníticas e "apófises e/ou veios" de material quartzo feldspáticos que cortam o bandamento gnáissico. O bandamento é formado por bandas lepidoblásticas a nematoblásticas constituídas por biotita e anfibólio, às vezes, anfibolíticas com texturas nematoblásticas e bandas leucocráticas quartzo feldspáticas, com alguma biotita e muscovita exibindo textura granolepidoblásticas.

As rochas que constituem o Ortognaisse Pontalina possuem como minerais essenciais, quartzo $(5-35 \%)$, microclínio (0 - 45\%), oligoclásio/andesina (17 - 50\%), biotita $(0-15 \%)$, muscovita/sericita $(0-6 \%)$, anfibólio $(0-20 \%)$, epídoto $(2-10 \%)$. Como minerais acessórios e ou secundários encontram-se ainda granada, carbonato, titanita, clorita, apatita, allanita, rutilo, minerais opacos (magnetita, hematita, ilmenita, sulfetos, etc.) e zircão. A composição modal desses ortognaisses indica o campo dos tonalitos a granodioritos, com porçôes monzograníticas a sienograníticas e mais raramente quartzo dioríticas.

O plagioclásio possui composição variando entre oligoclásio/andesina cálcica, com coroas albíticas em alguns cristais. Constitui cristais pequenos a médios, normalmente anedrais a subedrais, equidimensionais a subtabulares, às vezes, com forma lenticular a sigmoidal, parcialmente ou bem orientados, exibindo localmente recristalização. Ocorre também como massas de granulação fina, por vezes constituindo lóbulos mirmequíticos ou formando cordôes intersticiais aos cristais de feldspato potássico. Os limites dos cristais são retos a lobulados e localmente exibem textura de equilíbrio. O contato com o feldspato potássico pode apresentar uma delgada coroa albítica. Geminação polissintética ou simples bem definida foi raramente observada. Os cristais contêm inclusas poucas palhetas de sericita/muscovita fina e epídoto, às vezes, contêm inclusões arredondadas de quartzo. Os cristais inequidimensionais estão orientados. Alguns cristais são antipertíticos em machas por corrosão e mostram grau variado de sasssuritização, gerando sericita relativamente grossa (muscovita fina), epídoto, carbonato e clorita.

O microclínio ocorre sob a forma de cristais anedrais, por vezes com geminação em grade característica. Ocorrem como cristais pequenos a médios, sendo que os porfiroclástos podem exibir geminação Carlsbad, formas elípticas, extinção ondulante e recristalização. São comumente pertíticos em fios com pequena quantidade de albita. As relaçóes texturais observadas sugerem que o microclínio deva ter englobado e corroído o plagioclásio e foi posteriormente invadido por lóbulos mirmequíticos. Nas porçôes mais deformadas também mostram extinção ondulante com recristalização parcial resultando em cristais lenticulares.

O quartzo constitui cristais anedrais, com dimensóes menores que $1 \mathrm{~mm}$ e formato alongados. Normalmente estão orientados na foliação principal, chegando a formar trilhas e ribbons policristalinos. Constitui agregados policristalinos de contato lobulado, com variaçóes locais para poligonal e engrenado, relativamente equigranular a inequigranular serial. Também ocorrem inclusos por outros minerais, evidenciando ser de reação e aparece como cristais intersticiais, formando difusas concentrações sugerindo ter entrado nos sistema (mobilizados pré- a sin-cinemáticos). Alguns agregados policristalinos milimétricos de textura engrenada a lobulada e granulação média pouco inferior a $500 \mu \mathrm{m}$, evidenciam tratar-se de cristais maiores recristalizados. Os cristais maiores podem apresentar extinção ondulante leve à moderada, acompanhada de recuperação grossa, evidenciando que após a forte deformação dúctil a temperatura continuou relativamente alta.

As muscovitas formam palhetas tabulares, normalmente menores que $1 \mathrm{~mm}$, chegando a atingir $2 \mathrm{~mm}$ de comprimento, isoladas ou formando agregados de poucos cristais. Exibem grau de orientação variando de forte a incipiente e mostram ter substituído biotita e plagioclásio tardi-tectonicamente. Às vezes, aparecem nos planos de concentração da deformação substituindo biotita, crescendo sobre esta, juntamente com sericita sobre o plagioclásio. Ocorre disposta intersticialmente e localmente deformada, moldando-se a clastos mais competentes e maiores (feldspatos). A sericita ocorre sob a forma de minúsculas palhetas dispersas no interior do plagioclásio ou intersticialmente.

A biotita apresenta cor marrom esverdeado a amarelo pálido, forma de palhetas tabulares a irregulares. Ocorre sob a forma de cristais pequenos a médios bem orientados, localmente formando agregados policristalinos, com cristais exibindo contato equilibrado, de forma similar a muscovita. Forma difusas lâminas e/ou bandas. Como a muscovita fina/sericita também aparece no interior do plagioclásio. Também se encontra parcialmente cloritizada e substituída por muscovita e epídoto.

O epídoto forma cristais anedrais a subedrais, prismáticos e pequenos a médios. Ocorrem dispostos intersticialmente e/ou sobre biotita ou junto à clorita, titanita e opacos. Raramente ocorre como pequenos cristais no interior do plagioclásio ou com dimensóes relativamente grandes associados à muscovita. Chega a atingir mais de $1,5 \mathrm{~mm}$ de comprimento e/ou diâmetro, porém normalmente constitui agregados de granulação fina, que podem formar 
cordōes que emolduram o plagioclásio. Às vezes, possui bordas simplectíticas e cresce sobre os outros minerais, em especial o anfibólio e plagioclásio.

A hornblenda ocorre sob a forma de cristais pequenos a médios tabulares a irregulares (anedrais a subedrais), bem orientados e corroídos por biotita. Possui pleocroísmo forte verde oliva $(\beta)>$ verde azulado $(\gamma)$ e amarelo esverdeado pálido $(\alpha)$.

A allanita aparece como raros e pequenos cristais metamicticos e arredondados, frequentemente como coroas de epídoto.

A titanita ocorre sob a forma de cristais pequenos a médios (menores que 0,2 $\mathrm{mm}$ ), euedrais a anedrais e frequentemente intercresce com rutilo, e alguns cristais possuem agregados de rutilo nas bordas, sugerindo que o rutilo é tardi-recristalização da titanita. A titanita é levemente radioativa e chega a formar halos pleocroícos no anfibólio e na biotita. Às vezes, mostrando leve alteração para leucoxênio. Ocorre localmente associada à cloritizaçáo da biotita. Forma agregados policristalino ou cristais anedrais intercrescidos com opacos pulverulentos. Chega a formar trilhas e delgadas lentes associadas com bandas mais ricas em epídoto.

O rutilo possivelmente está associado à formação do epídoto, ligado a falta de Ca no retrometamorfismo.

O zircão ocorre sob a forma de minúsculos cristais anedrais a subedrais normalmente arredondado, zonados ou não.

Os minerais opacos constituem pequenos cristais anedrais a quadráticos e mostram ser representados, principalmente, por pirita e/ou magnetita que está parcialmente a totalmente alterada para óxido/hidróxido de ferro. Ocorrem como raras pontuaçóes anedrais ou intersticialmente em planos de fratura. Secundariamente aparece ilmenita.

A apatita ocorre sob a forma de cristais anedrais a subedrais, pequenos a médios, chegando a atingir quase $1 \mathrm{~mm}$ de comprimento, dispersos pela lâmina. A clorita constitui palhetas irregulares a subtabulares, evidenciando tratar-se de biotita alterada, podendo ser neoformada intersticialmente e sobre plagioclásio. Também ocorre substituindo biotita. $\mathrm{O}$ carbonato ocorre sob a forma de cristais anedrais a subedrais (romboédrico) e está disposto sobre o plagioclásio e intersticialmente, onde atinge as maiores dimensóes.

\section{GEOQUÍMICA DO ORTOGNAISSE PONTALINA}

Foram selecionadas 11 amostras do ortognaisse Pontalina para estudos litogeoquímicos de elementos maiores, traços e terras raras (Fig. 3 e Tab. 1, 2 e 3). As análises químicas (rocha total) foram realizadas pelo Laboratório Acme (Analytical Laboratories LTD, Vancouver, Canadá), utilizando os métodos 4A (ICP-ES) e 4B (ICP-MS), seguindo a rotina convencional de britagem e moagem realizadas no Laboratório de Preparação de Amostras do Departamento de Petrologia (DPM) do Instituto de Geociências e Ciências Exatas (IGCE) da Universidade Estadual Paulista Júlio de Mesquita Filho (UNESP). Os elementos maiores $\left(\mathrm{SiO}_{2}, \mathrm{TiO}_{2}, \mathrm{Al}_{2} \mathrm{O}_{3}, \mathrm{Fe}_{2} \mathrm{O}_{3}, \mathrm{MnO}\right.$, $\mathrm{MgO}, \mathrm{CaO}, \mathrm{Na}_{2} \mathrm{O}, \mathrm{K}_{2} \mathrm{O}$ e $\mathrm{P}_{2} \mathrm{O}_{5}$ ) foram obtidos por espectrômetro de emissão em plasma indutivamente acoplado (ICP-ES), após fusão utilizando metaborato/tetraborado de lítio e digestão em ácido nítrico diluído, sendo a perda ao fogo (LOI) determinada pela diferença de peso da amostra antes e depois do aquecimento a $1.000^{\circ} \mathrm{C}$ por 4 horas. Os elementos traços (Cs, Rb, Ba, Th, U, Nb, Ta, Sr, Zr, Hf, Y) e terras raras (La, Ce, Pr, Nd, Sm, Eu, Gd, Tb, Dy, Ho, Er, Tm, Yb, LU) foram analisados no espectrômetro de massa em plasma indutivamente acoplado (ICP-MS), após fusão utilizando metaborato/tetraborado de lítio e digestão em ácido nítrico, sendo que para os metais preciosos e base $(\mathrm{Cd}, \mathrm{Cu}, \mathrm{Mo}, \mathrm{Ni}, \mathrm{Pb}, \mathrm{Tl}, \mathrm{Zn})$ a digestão foi por água

Tabela 1. Elementos maiores (\%) analisados no ortognaisse Pontalina

\begin{tabular}{l|c|c|c|c|c|c|c|c|c|c|c}
\hline Amostra & G1 & G2 & G3 & G4 & G5 & G6 & G7 & G8 & G9 & G10 & G11 \\
\hline $\mathrm{SiO}_{2}$ & 71,15 & 60,69 & 65,62 & 55,74 & 67,39 & 60,01 & 55,13 & 65,15 & 72,90 & 70,30 & 73,51 \\
\hline $\mathrm{TiO}_{2}$ & 0,44 & 0,94 & 0,64 & 1,20 & 0,45 & 1,00 & 1,23 & 0,77 & 0,25 & 0,58 & 0,32 \\
\hline $\mathrm{Al}_{2} \mathrm{O}_{3}$ & 14,44 & 17,44 & 17,15 & 17,96 & 15,04 & 18,05 & 18,00 & 16,20 & 14,24 & 14,52 & 16,15 \\
\hline $\mathrm{Fe}_{2} \mathrm{O}_{3}$ & 3,53 & 6,96 & 4,84 & 8,49 & 4,17 & 6,88 & 8,22 & 5,29 & 2,51 & 4,84 & 1,37 \\
\hline $\mathrm{MnO}$ & 0,06 & 0,13 & 0,08 & 0,14 & 0,09 & 0,10 & 0,11 & 0,08 & 0,03 & 0,06 & 0,02 \\
\hline $\mathrm{MgO}$ & 0,76 & 2,33 & 1,46 & 3,49 & 2,13 & 2,12 & 4,77 & 1,55 & 0,53 & 2,03 & 0,67 \\
\hline $\mathrm{CaO}$ & 2,42 & 5,54 & 4,00 & 6,84 & 3,77 & 5,68 & 7,71 & 3,61 & 1,75 & 2,24 & 0,02 \\
\hline $\mathrm{Na}_{2} \mathrm{O}$ & 3,17 & 3,65 & 3,58 & 3,76 & 3,98 & 3,54 & 3,15 & 3,84 & 3,32 & 3,03 & 0,23 \\
\hline $\mathrm{K}_{2} \mathrm{O}$ & 3,92 & 2,18 & 2,38 & 2,17 & 2,85 & 2,47 & 1,59 & 3,24 & 4,38 & 2,36 & 4,87 \\
\hline $\mathrm{P}_{2} \mathrm{O}_{5}$ & 0,11 & 0,13 & 0,26 & 0,20 & 0,15 & 0,14 & 0,09 & 0,27 & 0,08 & 0,03 & 0,01 \\
\hline Total & 100 & 100 & 100 & 100 & 100 & 100 & 100 & 100 & 100 & 100 & 100 \\
\hline ACNK & 1,04 & 0,95 & 1,09 & 0,86 & 0,91 & 0,96 & 0,86 & 0,99 & 1,06 & 1,25 & 2,84 \\
\hline
\end{tabular}


régia. $\mathrm{O}$ tratamento dos dados geoquímicos e a construção de diagramas foram realizados com emprego do programa MINPET versão 2.02 (Richard 1995).

As rochas que compóem a Unidade do Ortognaisse Pontalina apresentam grande variação no conteúdo total de $\mathrm{SiO}_{2}(55,13$ - 73,51\%, composição intermediária a ácida), $\mathrm{FeO}_{\mathrm{T}}(1,23$ - 7,64\%), $\mathrm{MgO}(0,53$ - 4,77\%), $\mathrm{CaO}(0,02-7,71 \%)$, pequena variação no teor $\mathrm{de}_{2} \mathrm{Al}_{3}$
(14,24 - 18,05\%) e $\mathrm{TiO}_{2}(0,25$ - 1,23\%), altos conteúdos em $\mathrm{Na}_{2} \mathrm{O}(3,15-3,98 \%$, com exceção da amostra G11 que contém $0,23 \%)$ e $\mathrm{K}_{2} \mathrm{O}(1,59-4,87 \%)$ e baixos teores de $\mathrm{MnO}(0,02-0,14 \%)$ e $\mathrm{P}_{2} \mathrm{O}_{5}(0,01-0,27 \%)$. Além disso, possuem teores baixos de $\mathrm{Nb}(4,80-12,50 \mathrm{ppm})$, Ta $(0,40-1,30 \mathrm{ppm})$, Hf (2,40 - 6,70 ppm), Ga (13,10 19,90 ppm), Y (4,6 - 51,9 ppm), baixos a médios de Rb $(59,20-118,70 \mathrm{ppm})$ e baixos a moderadamente altos de

Tabela 2. Elementos traços (ppm) analisados no ortognaisse Pontalina

\begin{tabular}{l|c|c|c|c|c|c|c|c|c|c|c}
\hline Amostra & G1 & G2 & G3 & G4 & G5 & G6 & G7 & G8 & G9 & G10 & G11 \\
\hline $\mathrm{Sc}$ & 5,0 & 20,0 & 5,0 & 20,0 & 9,0 & 15,0 & 23,0 & 7,0 & 2,0 & 9,0 & 2,0 \\
\hline $\mathrm{V}$ & 42,0 & 130,0 & 46,0 & 175,0 & 66,0 & 120,0 & 193,0 & 65,0 & 17,0 & 51,0 & 8,0 \\
\hline $\mathrm{Cr}$ & 13,7 & 13,7 & 13,7 & 13,7 & 41,1 & 13,7 & 41,1 & 13,7 & 13,7 & 47,9 & 13,7 \\
\hline $\mathrm{Co}$ & 5,8 & 17,0 & 6,7 & 24,9 & 11,2 & 16,0 & 29,9 & 10,5 & 2,9 & 10,4 & 0,8 \\
\hline $\mathrm{Ni}$ & 3,6 & 12,1 & 3,4 & 22,2 & 34,0 & 8,8 & 42,4 & 9,9 & 3,9 & 23,0 & 0,7 \\
\hline $\mathrm{Cu}$ & 9,9 & 28,3 & 3,5 & 24,2 & 2,6 & 27,2 & 39,9 & 7,7 & 16,4 & 16,4 & 6,4 \\
\hline $\mathrm{Zn}$ & 46,0 & 88,0 & 55,0 & 64,0 & 47,0 & 71,0 & 37,0 & 72,0 & 25,0 & 73,0 & 4,0 \\
\hline $\mathrm{Rb}$ & 118,7 & 98,7 & 72,6 & 67,1 & 85,8 & 104,2 & 59,2 & 74,2 & 98,4 & 83 & 86,8 \\
\hline $\mathrm{Cs}$ & 3,8 & 6,9 & 2,6 & 5,1 & 4,5 & 6,3 & 3,3 & 2,9 & 6,6 & 1,3 & 1,2 \\
\hline $\mathrm{Sr}$ & 264,1 & 388,8 & 450,2 & 418,5 & 361,9 & 420,1 & 447,2 & 449,0 & 265,7 & 311,3 & 13,4 \\
\hline $\mathrm{Ba}$ & 676,0 & 556,0 & 814,0 & 484,0 & 652,0 & 562,0 & 279,0 & 1139,0 & 1400,0 & 696,0 & 1572,0 \\
\hline $\mathrm{Y}$ & 18,2 & 51,9 & 17,5 & 29,5 & 19,8 & 27,8 & 18,7 & 26,6 & 6,7 & 8,1 & 4,6 \\
\hline $\mathrm{Zr}$ & 153,0 & 96,2 & 249,9 & 103,8 & 126,5 & 129,4 & 73,4 & 273,2 & 186,7 & 186,7 & 216,1 \\
\hline $\mathrm{Hf}$ & 4,7 & 2,8 & 6,2 & 2,9 & 3,6 & 3,6 & 2,4 & 6,7 & 5,1 & 5,4 & 6,2 \\
\hline $\mathrm{Nb}$ & 8,6 & 10,8 & 7,1 & 8,7 & 7,9 & 10,4 & 5,6 & 10,2 & 4,8 & 12,5 & 12,4 \\
\hline $\mathrm{Ta}$ & 0,7 & 1,3 & 0,4 & 0,7 & 0,6 & 0,7 & 0,6 & 0,7 & 0,8 & 0,5 & 1 \\
\hline $\mathrm{Pb}$ & 2,0 & 3,4 & 4,1 & 3,4 & 2,4 & 2,1 & 6,6 & 3,7 & 5,6 & 5,3 & 6,7 \\
\hline $\mathrm{Th}$ & 18,2 & 3,0 & 9,1 & 4,6 & 9,1 & 5,8 & 3,9 & 10,2 & 9,6 & 6,4 & 7,7 \\
\hline $\mathrm{U}$ & 2,0 & 2,3 & 2,5 & 3,3 & 1,5 & 4,2 & 2 & 1,5 & 4,5 & 0,6 & 1,1 \\
\hline $\mathrm{Ga}$ & 15,0 & 19,6 & 19,1 & 18,4 & 14,3 & 19,9 & 19 & 17,4 & 13,1 & 16,7 & 14,9 \\
\hline $\mathrm{Be}$ & 2,0 & 2,0 & 2,0 & 2,0 & 1,0 & 2,0 & 2,0 & 2,0 & 1,0 & 1,0 & 2,0 \\
\hline $\mathrm{W}$ & 0,7 & 0,5 & 0,5 & 0,6 & 0,6 & 0,6 & 0,5 & 0,5 & 0,7 & 0,5 & 1,5 \\
\hline $\mathrm{Sn}$ & 2,0 & 3,0 & 2,0 & 3,0 & 1,0 & 3,0 & 2,0 & 2,0 & 1,0 & 1,0 & 1,0 \\
\hline $\mathrm{Mo}$ & 0,5 & 0,5 & 0,3 & 0,5 & 0,6 & 0,4 & 0,4 & 0,2 & 0,4 & 1 & 2,5 \\
\hline
\end{tabular}

Tabela 3. Elementos terras raras (ppm) analisados no ortognaisse Pontalina

\begin{tabular}{l|c|c|c|c|c|c|c|c|c|c|c}
\hline Amostra & G1 & G2 & G3 & G4 & G5 & G6 & G7 & G8 & G9 & G10 & G11 \\
\hline $\mathrm{La}$ & 24,80 & 11,10 & 42,80 & 15,20 & 33,20 & 24,60 & 8,30 & 53,50 & 23,40 & 29,10 & 18,30 \\
\hline $\mathrm{Ce}$ & 48,70 & 22,10 & 73,90 & 37,30 & 54,30 & 43,80 & 21,80 & 113,30 & 44,50 & 42,70 & 33,90 \\
\hline $\mathrm{Pr}$ & 5,33 & 3,86 & 9,30 & 5,08 & 7,14 & 5,97 & 3,20 & 12,18 & 4,53 & 5,88 & 3,19 \\
\hline $\mathrm{Nd}$ & 20,60 & 18,50 & 34,70 & 23,70 & 27,40 & 24,20 & 15,30 & 44,50 & 15,80 & 22,80 & 10,70 \\
\hline $\mathrm{Sm}$ & 4,27 & 5,95 & 5,45 & 5,68 & 4,86 & 5,15 & 3,88 & 7,53 & 2,18 & 3,29 & 1,70 \\
\hline $\mathrm{Eu}$ & 0,99 & 1,89 & 1,33 & 1,58 & 1,22 & 1,52 & 1,26 & 1,92 & 0,98 & 1,36 & 0,45 \\
\hline $\mathrm{Gd}$ & 4,19 & 7,29 & 4,25 & 5,67 & 3,98 & 5,47 & 3,73 & 6,25 & 1,50 & 2,67 & 1,15 \\
\hline $\mathrm{Tb}$ & 0,70 & 1,52 & 0,61 & 0,95 & 0,63 & 0,93 & 0,65 & 0,95 & 0,21 & 0,31 & 0,18 \\
\hline $\mathrm{Dy}$ & 3,65 & 9,33 & 3,24 & 5,60 & 3,40 & 4,87 & 3,52 & 4,88 & 1,25 & 1,34 & 0,84 \\
\hline $\mathrm{Ho}$ & 0,67 & 1,87 & 0,57 & 1,09 & 0,68 & 0,94 & 0,67 & 0,90 & 0,24 & 0,25 & 0,14 \\
\hline $\mathrm{Er}$ & 1,72 & 5,40 & 1,80 & 3,20 & 1,83 & 2,60 & 1,86 & 2,55 & 0,78 & 0,71 & 0,49 \\
\hline $\mathrm{Yb}$ & 0,24 & 0,86 & 0,30 & 0,51 & 0,30 & 0,37 & 0,27 & 0,39 & 0,15 & 0,11 & 0,08 \\
\hline $\mathrm{Lu}$ & 1,44 & 5,42 & 2,02 & 3,27 & 2,00 & 2,17 & 1,77 & 2,45 & 1,15 & 0,74 & 0,57 \\
\hline & 0,21 & 0,74 & 0,30 & 0,50 & 0,30 & 0,31 & 0,25 & 0,35 & 0,21 & 0,12 & 0,13 \\
\hline
\end{tabular}


$\mathrm{Zr}(73,4$ - 273,2 ppm), V (8,0 - 193,0 ppm), Sr (13,4 450,2 ppm), com altos teores de Ba $(279,00-1.572,0$ ppm). O conteúdo de $\mathrm{U}$, Th e $\mathrm{Pb}$ varia entre $0,6-4,5 \mathrm{ppm}$, 3,0 - 18,0 ppm e 2,0 - 6,7 ppm, respectivamente. O conjunto de amostras analisadas, nos diagramas tipo Harker forma trends bem definidos (Fig. 4), apresentando correlaçôes geoquímicas positivas, mostrando que houve um aumento nos teores de $\mathrm{K}_{2} \mathrm{O}, \mathrm{Ba}, \mathrm{Rb}, \mathrm{Zr}$, Th com o aumento de $\mathrm{SiO}_{2}$, e correlaçóes negativas, entre $\mathrm{SiO}_{2}$ e $\mathrm{TiO}_{2}, \mathrm{Al}_{2} \mathrm{O}_{3}$ FeOT, MnO, MgO, CaO, Y, V, Sc e Ga, indicando o grau de evolução e o caráter cogenético entre as amostras. Em relação ao $\mathrm{Na}_{2} \mathrm{O}, \mathrm{P}_{2} \mathrm{O}_{5}$, Cs, $\mathrm{U}$ e $\mathrm{Nb}$ x $\mathrm{SiO}_{2}$, não foram observadas correlaçóes.
Apresentam composição calcioalcalina, metaluminosa a peraluminosa, com razáo molecular $\mathrm{A} / \mathrm{CNK}$ de 0,86 a 1,25 (Figs. 5A e B). A composição normativa (CIPW) indica, como minerais principais: quartzo, ortoclásio, albita, anortita e subordinadamente hiperstênio, diopsídio e coríndon. A composição, com base no conteúdo de feldspato normativo, varia entre tonalito-granodiorito a granito (Fig. 5C). No diagrama discriminante R2 x R1 (De La Roche et al.1980), as rochas são classificadas como diorito, tonalito e granodiorito (Fig. 5D).

Os padrôes de distribuição de alguns elementos analisados normalizados pelo manto primitivo (Taylor \& MacLennan, 1985) revelam enriquecimento em elementos

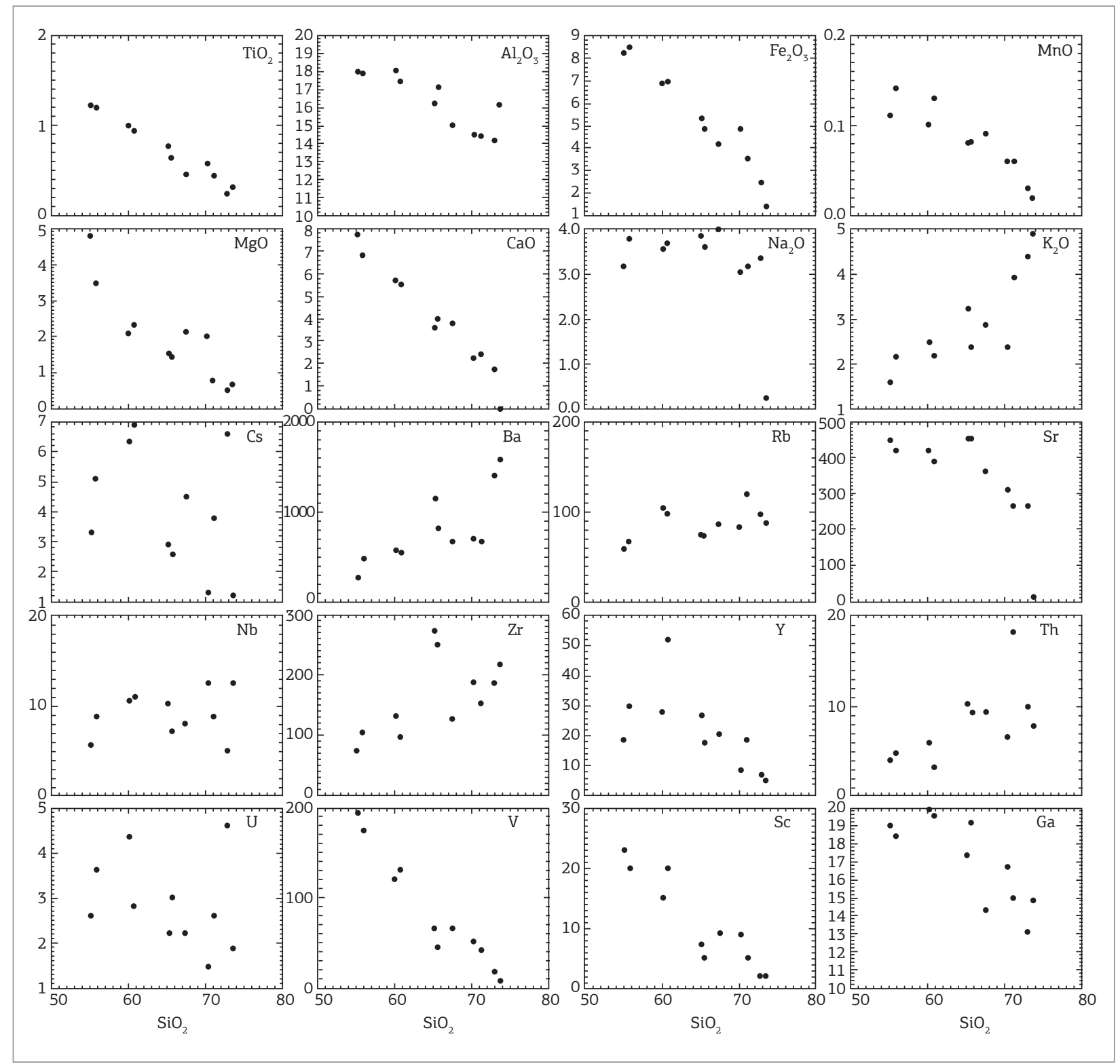

Figura 4. Diagramas tipo Harker $\mathrm{SiO}_{2}$ versus. elementos maiores $\left(\mathrm{TiO}_{2}, \mathrm{Al}_{2} \mathrm{O}_{3}, \mathrm{Fe}_{2} \mathrm{O}_{3} \mathrm{~T}, \mathrm{MnO}, \mathrm{MgO}, \mathrm{CaO}, \mathrm{Na}_{2} \mathrm{O}\right.$ e $\left.\mathrm{P}_{2} \mathrm{O}_{5}\right)$ e traços (Cs, Ba, Rb, Sr, Nb, Zr, Y, Th, U, V, Sc, Ga). 
litófilos de raio iônico grande (LILE - como Cs, Ba, Rb, $K$, etc) em relação a elementos de alto campo de força (HFSE - como Nb, Ta, P, Zr, Ti e Y) e médias a fracas anomalias de Nb, Ta, P e Ti (Fig. 6A). O conteúdo total de ETR é baixo $\left(\right.$ SETR $_{\text {Total }}=66,46$ a 251,65 ppm), com maior conteúdo em elementos terras raras leves (ETRL) em relação aos elementos terras raras pesados (ETRP) (SETRL = 53,74 a 232,93 ppm e SETRP $=3,58$ a 32,43 ppm). A normalização dos ETR pelo manto primitivo (Taylor \& MacLennan 1985) indicam que os ETRL e os ETRP possuem concentraçôes entre 2,0 - 77,0 e 1,0 - 22,0 vezes acima do mato primitivo, respectivamente (Fig. 6B).
O padrão de distribuição de ETR das amostras analisadas apresenta fracionamento entre ETRL $\left(\mathrm{La}_{\mathrm{N}} / \mathrm{Eu}_{\mathrm{N}}=\right.$ $1,44-7,87)$ e ETRP $\left(\mathrm{Gd}_{\mathrm{N}} / \mathrm{Lu}_{\mathrm{N}}=0,89-2,48\right)$, exibindo em ambos os casos um padrão inclinado. No geral, a distribuição entre ETRL e ETRP mostra um fracionamento em relação aos ETRL e ETRP $\left(\mathrm{La}_{\mathrm{N}} / \mathrm{Lu}_{\mathrm{N}}=1,62-16,46\right)$, exibindo discretas anomalias negativas de $\mathrm{Eu}^{*}(0,71-0,88)$, com exceção de uma amostra. Três amostras mostram um padrão de distribuição convexo de ETRP, com menores conteúdos em ETRP em relação às outras amostras, com forte fracionamento de ETRL em relação à ETRP (razôes $\mathrm{La}_{\mathrm{N}} / \mathrm{Eu}_{\mathrm{N}}=5,23-9,94, \mathrm{Gd}_{\mathrm{N}} / \mathrm{Lu}_{\mathrm{N}}=0,89-2,76 \mathrm{e} \mathrm{La}_{\mathrm{N}} /$
A

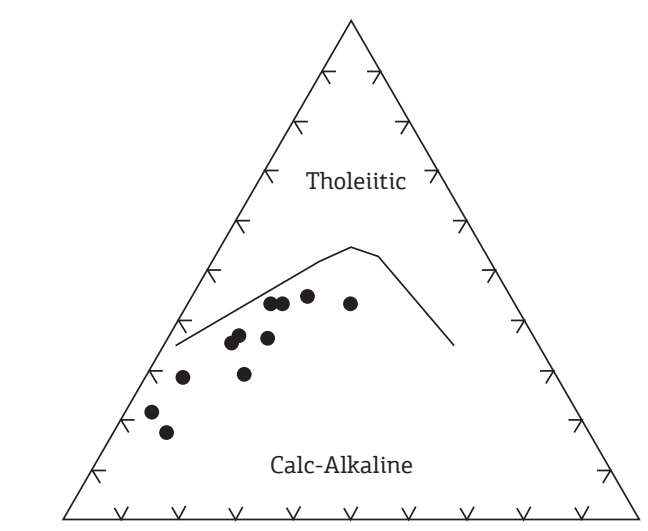

$\mathrm{Na}_{2} \mathrm{O}+\mathrm{K}_{2} \mathrm{O}$

C

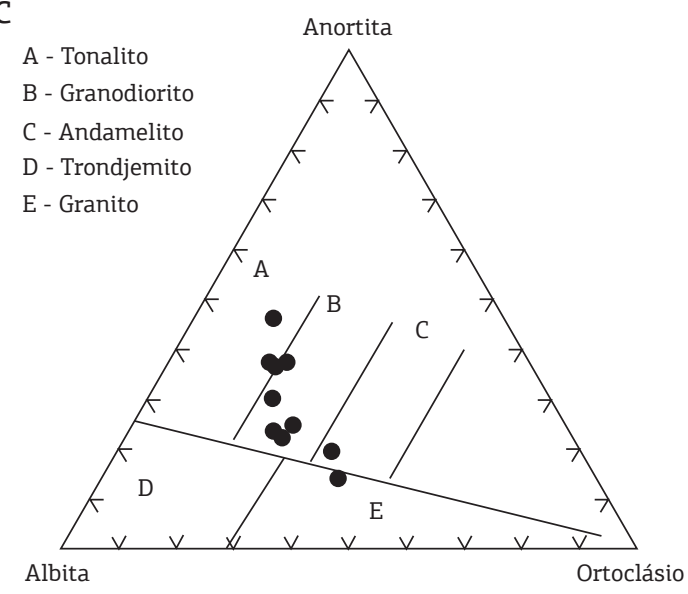

B

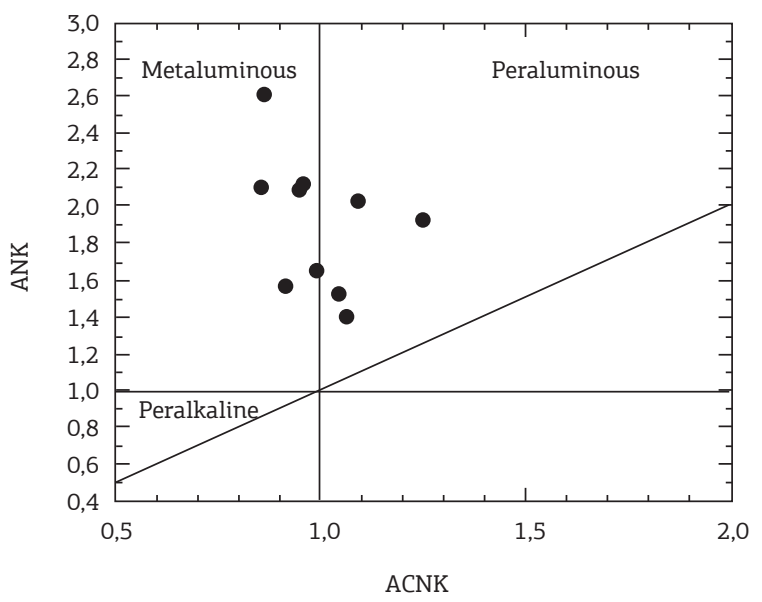

D

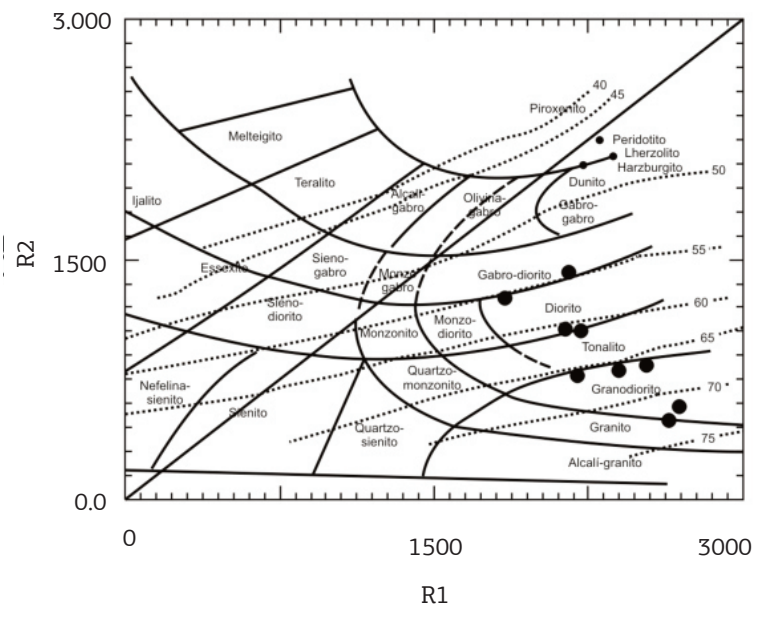

Figura 5. (A) Diagrama AFM (Irvine \& Baragar 1971, $\mathrm{A}=\mathrm{Na}_{2} \mathrm{O}+\mathrm{K}_{2} \mathrm{O} ; \mathrm{F}=\mathrm{FeO}_{\mathrm{T}}, \mathrm{M}=\mathrm{MgO}$ ) mostrando o caráter calcioalcalino dos ortognaisses da região. (B) Gráfico de classificação do índice de Shand (Maniar \& Piccoli, 1989) (C) gráfico de classificação baseado no teor de feldspato normativo (D) diagrama de classificação para rochas plutônicas Ri x R2 (De La Roche et al. 1980). 
$\left.\mathrm{Lu}_{\mathrm{N}}=12,0-26,12\right)$ e fracas anomalias positivas de Eu* (1,36 - 1,57). Estes dois padróes de ETR sugerem uma mistura de magmas mais diferenciados durante a evolução do ortognaisse Pontalina, ou mistura de magmas de fontes diferentes, o que parece ser menos provável.

Nos diagramas discriminantes $\mathrm{Rb}$ versus $\mathrm{Y}+\mathrm{Nb}$ e $\mathrm{Nb}$ versus Y (Pearce, Harris \& Tindle 1984), as amostras de ortognaisses da regiáo de Pontalina exibem composiçóes químicas semelhantes às rochas plutônicas geradas em arcos magmáticos com características sin-colisionais, fato também sugerido pela presença de anomalias de $\mathrm{Nb}$, Ta, P e Ti e baixos conteúdos de Y e $\mathrm{Yb}$, bem como enriquecimento em LILE em relação a HFSE (Fig. 7).

\section{GEOCRONOLOGIA E DADOS ISOTÓPICOS SM-ND DO ORTOGNAISSE PONTALINA}

A amostra (G1) foi selecionada para a determinação de Idades Modelo $\left(\mathrm{T}_{\mathrm{DM}}\right)$ em rocha total e para a determinação de idade U/Pb em zircão (análise por LA-ICP-MS). A amostra analisada corresponde a uma amostra de biotitamuscovita gnaisse granodiorítico com fenocristais de feldspatos, com textura ígnea preservada. A amostra selecionada foi desagregada e sua granulometria reduzida via britador, para separação da fração inferior a $500 \mu \mathrm{m}$. Os minerais pesados presentes nesta fração foram concentrados no Laboratório de Separação de Zircão do Departamento

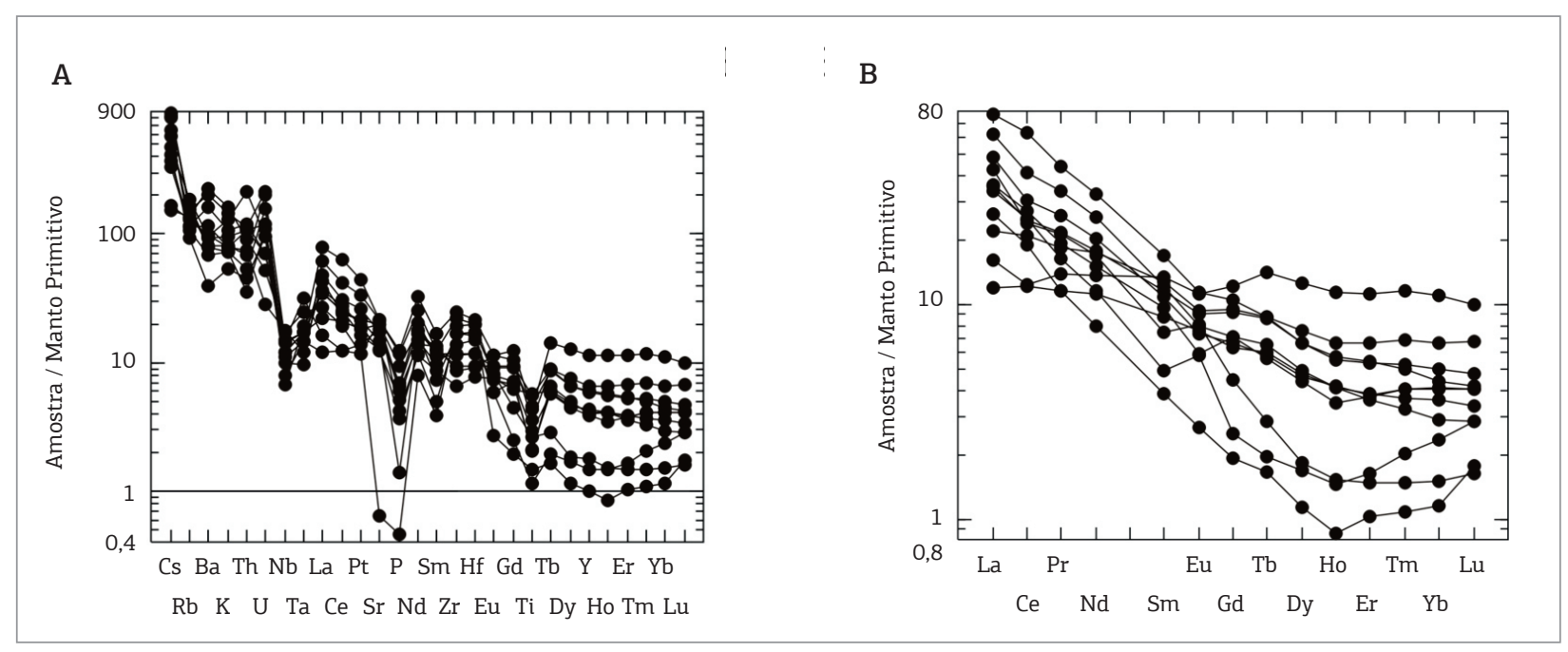

Figura 6. Diagramas tipo aranha (spider diagram) mostrando os padrões de distribuição de elementos menores e traços (A) e elementos terras raras (B) normalizados pelo Manto Primitivo (Taylor \& MacLennan 1985) dos ortognaisses da região.
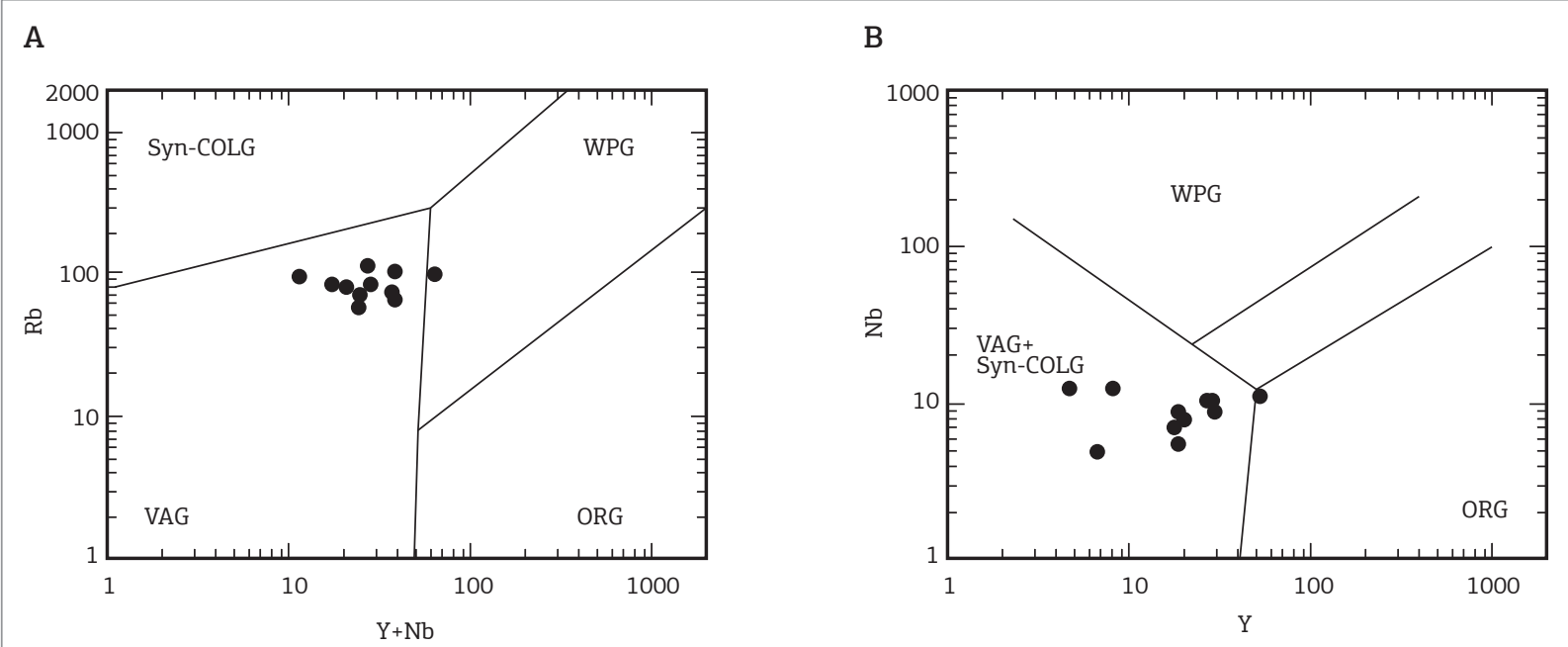

Figura 7. Gráficos discriminantes de ambientes tectônicos (Pearce, Harris \& Tindle 1984) para os ortognaisses da região. 
de Petrologia e Metalogenia, da UNESP, utilizando bateias mecanizadas. Após a separação magnética, o concentrado foi encaminhado ao Laboratório de Geocronologia, do Instituto de Geociências, da Universidade Federal de Brasília (UnB), onde os grãos de zircão foram separados manualmente em lupa binocular. Para a confecção dos mounts não foi realizado nenhum processo de seleção dos zircóes, visando uma amostragem randômica das populaçóes existentes na amostra. Os mounts foram confeccionados com resina epóxi (a frio), desgastados e polidos para exposição do interior dos grãos. As determinaçóes realizadas no LAM-ICP-MS foram feitas segundo o procedimento apresentado por Buhn et al. (2009). Para a limpeza dos mounts foi utilizado banho com ácido nítrico diluído (3\%), água Nanopure ${ }^{\circledR}$ em ultrassom e por último em acetona para extração de qualquer resíduo de umidade. As leituras das razões foram realizadas no espectrômetro de massas multicoletor, modelo Thermo Finnigan Neptune, do Laboratório de Geocronologia do Instituto de Geociências da UnB. Os resultados das análises estão apresentados na Tab. 4 e a localização da amostra na Fig. 3.

Parte da amostra (G1), após da desagregação, foi pulverizada e enviada para o Laboratório de Geocronologia do Instituto de Geociências da UnB, onde foi realizada a análise isotópica de $\mathrm{Sm}-\mathrm{Nd}$ segundo o método descrito por Gioia \& Pimentel (2000). Para a preparação cerca de $50 \mathrm{mg}$ da amostra foi misturada a solução traçadora mista de ${ }^{149} \mathrm{Sm}$ e ${ }^{150} \mathrm{Nd}$. Após a mistura, a amostra foi digerida em cápsula de Savillex através de sucessivos ataques de ácido fluorídrico $(\mathrm{HF})$, nítrico $\left(\mathrm{HNO}_{3}\right)$ e clorídrico $(\mathrm{HCl})$. Após sucessivas etapas de lixiviação, os elementos lantanídios são separados pelos métodos convencionais através de colunas de troca iônica, confeccionadas em quartzo, utilizando resina BIO-RAD AG50wx8. Os conteúdos de $\mathrm{Sm}$ e $\mathrm{Nd}$ foram extraídos através de colunas de trocas catiônicas de Teflon e preenchidas com resina $\mathrm{LN}-\mathrm{Spec}$. Os sais de $\mathrm{Sm}$ e $\mathrm{Nd}$ são depositados em arranjos duplos de filamentos de rênio. As leituras das razóes foram realizadas no mesmo equipamento usado para a datação U-Pb. As incertezas para as razóes de $\mathrm{Sm} / \mathrm{Nd}$ e ${ }^{143} \mathrm{Nd} /{ }^{144} \mathrm{Nd}$ são inferiores a $\pm 0,5 \%(2 \sigma)$ e $\pm 0,005 \%(2 \sigma)$, respectivamente, baseados em repetidas análises nos padróes internacionais BHVO-1 e BCR-1. A razão ${ }^{143} \mathrm{Nd} /{ }^{144} \mathrm{Nd}$ foi normalizada em função da razão ${ }^{146} \mathrm{Nd} /{ }^{144} \mathrm{Nd}$ de 0,7219 . Os valores de TDM foram calculados usando o modelo de De Paolo (1981). Os resultados das análises estão apresentados na Tab. 5 .

A idade U-Pb de 681,5 \pm 7,7 Ma obtida para o ortognaisse Pontalina pode ser interpretada como idade de sua cristalização (Fig. 8A). As idades mais velhas obtidas

Tabela 4. Resultados analíticos obtidos para zircões datados com razões ${ }^{207} \mathrm{~Pb} /{ }^{206} \mathrm{~Pb}$ do ortognaisse Pontalina

\begin{tabular}{|c|c|c|c|c|c|c|c|c|c|c|c|c|c|c|c|c|c|}
\hline & $\begin{array}{c}f(206) \\
\%\end{array}$ & $\mathrm{~h} / \mathrm{U}$ & $6 / 4$ ratio & $\begin{array}{c}7 / 6 \\
\text { ratio }\end{array}$ & $\begin{array}{l}1 \mathrm{~s} \\
(\%)\end{array}$ & $\begin{array}{c}7 / 5 \\
\text { ratio }\end{array}$ & $\begin{array}{c}1 \mathrm{~s} \\
(\%)\end{array}$ & $\begin{array}{c}6 / 8 \\
\text { ratio }\end{array}$ & $\begin{array}{c}1 s \\
(\%)\end{array}$ & Rho & $7 / 6$ age & 1s (\%) & $1 / 5$ age & 1s (\%) & $6 / 8$ age & 1s $(\%$ & $\begin{array}{l}\text { Conc } \\
(\%)\end{array}$ \\
\hline & 0,08 & & & 0,062 & 0,816 & 0,970 & 1,301 & & & & & & & & & & \\
\hline & & & & & & & & & & & & & & & & & \\
\hline & & & & & & & & & & & & & & & & & \\
\hline & & & & & & & & & & & & & & & & & \\
\hline & & & & & & & & & & & & & & & & & \\
\hline & & & & 062 & & 779 & & & & & & & & & & & \\
\hline & & & & & & & & & & & & & & & & & \\
\hline & & & & 059 & & 347 & & & & & & & & & & & \\
\hline & & & & & & & & & & & & & & & & & \\
\hline & & & & 063 & & 959 & 1 & & & & & & & & & & \\
\hline & & & & & & & & & & & & & & & & & \\
\hline & & & & 62 & & 35 & 2 & & & & & & & & & & \\
\hline & & & & & C & & & & & & & & & & & & \\
\hline & & & & 061 & 0,913 & 0,916 & 1,546 & & 46 & 797 & & & & & & & \\
\hline & & & & & 0 , & & 1,6 & & & & & & & & & & \\
\hline & & & & & & 885 & & & & & & & & & & & \\
\hline & & & & 061 & 0,81 & & 1,6 & & & & & & & & & & \\
\hline & & & & 062 & 0,775 & 938 & 1,85 & & & & & & & & & & \\
\hline & & & & 0,062 & 0,864 & 0,908 & 1,59 & & 1,343 & 834 & & & & & & & \\
\hline & & 83 & & 0,062 & 5 & 0,836 & 2,03 & & & & & & & & & & \\
\hline & & & & 0,057 & 2,04 & & & & & & & & & & & & \\
\hline & & & & & 0,79 & 0,853 & 1,39 & & & & & & & & & & \\
\hline & & & & 0,061 & 0,735 & 0,939 & 1,3 & & & & & & & & & 582 & \\
\hline $36 \mathrm{Z24}$ & 031 &, 112 & 57886,291 & 0,061 & 1,089 & 0,869 & 2,373 & 0,103 & 2,107 & 0,942 & 652,121 & 23,202 & 635,085 & 11,141 & 630,309 & 12,646 & 96,655 \\
\hline
\end{tabular}


em alguns grãos de zircáo podem ser interpretadas como idades herdadas, provavelmente de grãos advindos das rochas encaixantes. Em relação às idades modelo $\mathrm{T}_{\mathrm{DM}}$, o resultado apresentado na Tab. 5 (1,25 Ga) é praticamente igual aos dados apresentados por Pimentel, Fuck \& Gioia (2000) e Navarro \& Zanardo (2007a) para os gnaisses do Arco Magmático de Goiás na regiáo de Pontalina, os quais obtiveram valores variando entre 0,90 e 1,26 Ga (Tab. 5). $\mathrm{O} \varepsilon_{\mathrm{Nd}(\mathrm{T})}(\mathrm{T}=681 \mathrm{Ma})$ é fracamente positivo a fracamente negativo $(+3,2$ e $-0,1)$, indicando um caráter primitivo para o magma original. As idades $\mathrm{T}_{\mathrm{DM}}$ e U-Pb e os valores $\varepsilon_{\mathrm{Nd}}(T)$ são semelhantes à de outras áreas do Arco Magmático de Goiás Figura (Figs. 8B e C).

Os dados geocronológicos, geoquímicos e isotópicos disponíveis mostram que o Arco Magmático de Goiás é resultado de um sistema de arcos de ilhas intraoceânicos, caracterizados por tonalitos a dioritos calcioalcalinos, e vulcânicas associadas, formados por dois eventos principais de acresção crustal, um entre - 900 a $800 \mathrm{Ma}$ e outro entre - 670 a $600 \mathrm{Ma}$ (Pimentel, Jost \& Fuck 2004, Laux et al. 2005). Na regiáo de Pontalina isócrona de rocha total Sm/ Nd (Pimentel, Fuck \& Gioia 2000) e idades U-Pb em zircão (Simôes 2005) revelam idades de cristalização de $762 \pm$ $77 \mathrm{Ma}$ (metavulcânica, Idade Sm-Nd em rocha total), $759 \pm$ $18 \mathrm{Ma}$ (muscovita gnaisse, idade U-Pb) e de $643 \pm 3,9$ (hornblenda-biotita gnaisse, idade U-Pb). Esses dados, associados à idade de $681 \pm 7,7$ apresentada neste trabalho, sugerem que as rochas da região ocorreu um episódio magmático entre 800 e 700 Ma e outro entre 700 e 600 Ma, como já descrito em outras regiōes do Arco Magmático de Goiás.

\section{CONCLUSÃO}

A maioria das idades U-Pb das rochas do Arco Magmático de Goiás se concentram no intervalo entre $900-800 \mathrm{Ma}$ e $640-600 \mathrm{Ma}$ (Fig. 8D), caracterizando dois períodos principais de acreçáo crustal. $\mathrm{O}$ intervalo entre $800-700 \mathrm{Ma}$ é considerado como um período de quiescência ígnea, e pode representar inclinação rasa da zona de subducção e limitada fusão da cunha do manto (Pimentel, Jost \& Fuck 2004). O ortognaisse Pontalina é constituído por rochas calcioalcalinas, metaluminosas a peraluminosas, de composiçáo variando de tonalito a granodiorito. Quimicamente as anomalias negativas de $\mathrm{Nb}, \mathrm{Ta}, \mathrm{P}$ e Ti e baixos conteúdos em elementos como $\mathrm{Nb}, \mathrm{Ta}, \mathrm{Y}$ e $\mathrm{Yb}$ sugerem que as rochas foram formadas em ambientes envolvendo subducção. As características isotópicas $\varepsilon_{\mathrm{Nd}(\mathrm{T})}$ e os dados geocronológicos U-Pb (idade de cristalização de $681 \mathrm{Ma}$ ) e Sm-Nd (exibindo idades modelo jovens de $\sim$ 1,2 Ga), com valores fracamente negativos a positivos de $\varepsilon_{\mathrm{Nd}(\mathrm{T})}$ $(+3,2$ e - $-0,1)$ mostram que o protólito desse gnaisse são magmas juvenis, formados no Neoproterozoico, em um sistema de arco de ilha, desenvolvido, durante um evento de acresção crustal na borda oeste do Cráton do

Tabela 5. Resultados isotópicos Sm-Nd para rochas da região de Pontalina

\begin{tabular}{|c|c|c|c|c|c|c|}
\hline Amostra & Sm(ppm) & $\mathrm{Nd}(\mathrm{ppm})$ & ${ }^{147} \mathrm{Sm} /{ }^{144} \mathrm{Nd}$ & ${ }^{143} \mathrm{Nd} /{ }^{144} \mathrm{Nd}$ & $\varepsilon_{\mathrm{Nd}(0)}$ & $\mathrm{T}_{\mathrm{DM}}(\mathrm{Ga})$ \\
\hline $\mathrm{G} 1^{\mathrm{GP}}$ & 5,574 & 27,651 & 0,1218 & $0,512284 \pm 12$ & $-6,91$ & 1,25 \\
\hline G11 ${ }^{* *, G P}$ & 1,635 & 9,010 & 0,1097 & $0,512209 \pm 07$ & $-8,37$ & 1,22 \\
\hline $\mathrm{G}_{11 \mathrm{~B}}{ }^{* *, \mathrm{GP}}$ & 1,563 & 8,475 & 0,1115 & $0,512197 \pm 06$ & $-8,60$ & 1,26 \\
\hline $\mathrm{G7}^{* *}$ & 12,163 & 53,166 & 0,1383 & $0,512600 \pm 10$ & $-0,74$ & 0,90 \\
\hline G9** & 12,079 & 67,700 & 0,1079 & $0,512383 \pm 19$ & $-4,97$ & 0,96 \\
\hline G24** & 2,524 & 10,260 & 0,1487 & $0,512569 \pm 07$ & $-1,35$ & 1,11 \\
\hline G25** & 3,322 & 22,786 & 0,0881 & $0,512173 \pm 08$ & $-9,07$ & 1,06 \\
\hline $\mathrm{G}^{25 B^{* *}}$ & 3,247 & 21,895 & 0,0896 & $0,512210 \pm 05$ & $-8,35$ & 1,03 \\
\hline G30** & 5,668 & 24,054 & 0,1424 & $0,512570 \pm 69$ & $-1,33$ & 1,02 \\
\hline $\mathrm{G} 41^{* *}$ & 4,001 & 17,467 & 0,1385 & $0,512549 \pm 06$ & $-1,74$ & 1,00 \\
\hline G42** & 3,122 & 13,013 & 0,1450 & $0,512579 \pm 13$ & $-1,15$ & 1,03 \\
\hline $\mathrm{A} 3^{* *}$ & 7,500 & 37,000 & 0,1225 & $0,512445 \pm 06$ & $-3,76$ & 1,00 \\
\hline $\mathrm{A} 10^{* *}$ & 5,328 & 26,961 & 0,1195 & $0,512372 \pm 21$ & $-5,19$ & 1,09 \\
\hline PONT1* & 7,343 & 45,090 & 0,0980 & $0,512317 \pm 23$ & $-6,26$ & 0,96 \\
\hline PONT2* & 8,403 & 41,540 & 0,1220 & $0,512438 \pm 07$ & $-3,90$ & 1,01 \\
\hline PONT3* & 3,807 & 21,960 & 0,1050 & $0,512296 \pm 45$ & $-6,67$ & 1,05 \\
\hline PONT4B* & 3,630 & 24,080 & 0,0910 & $0,512249 \pm 21$ & $-7,59$ & 0,99 \\
\hline PONT5* & 5,010 & 19,500 & 0,1550 & $0,512570 \pm 0.5$ & $-1,33$ & 1,23 \\
\hline PONT6* & 7,014 & 39,920 & 0,1060 & $0,512164 \pm 12$ & $-9,25$ & 1,24 \\
\hline $\mathrm{ALO1}^{*}$ & 5,891 & 27,700 & 0,1280 & $0,512219 \pm 20$ & $-8,17$ & 1,46 \\
\hline $\mathrm{ALO}^{*}$ & 3,771 & 18,680 & 0,1220 & $0,512365 \pm 12$ & $-5,33$ & 1,13 \\
\hline
\end{tabular}

*dados Pimentel et al. (2000b), **dados de Navarro e Zanardo (2007a). GP: amostras do ortognaisse Pontalina 


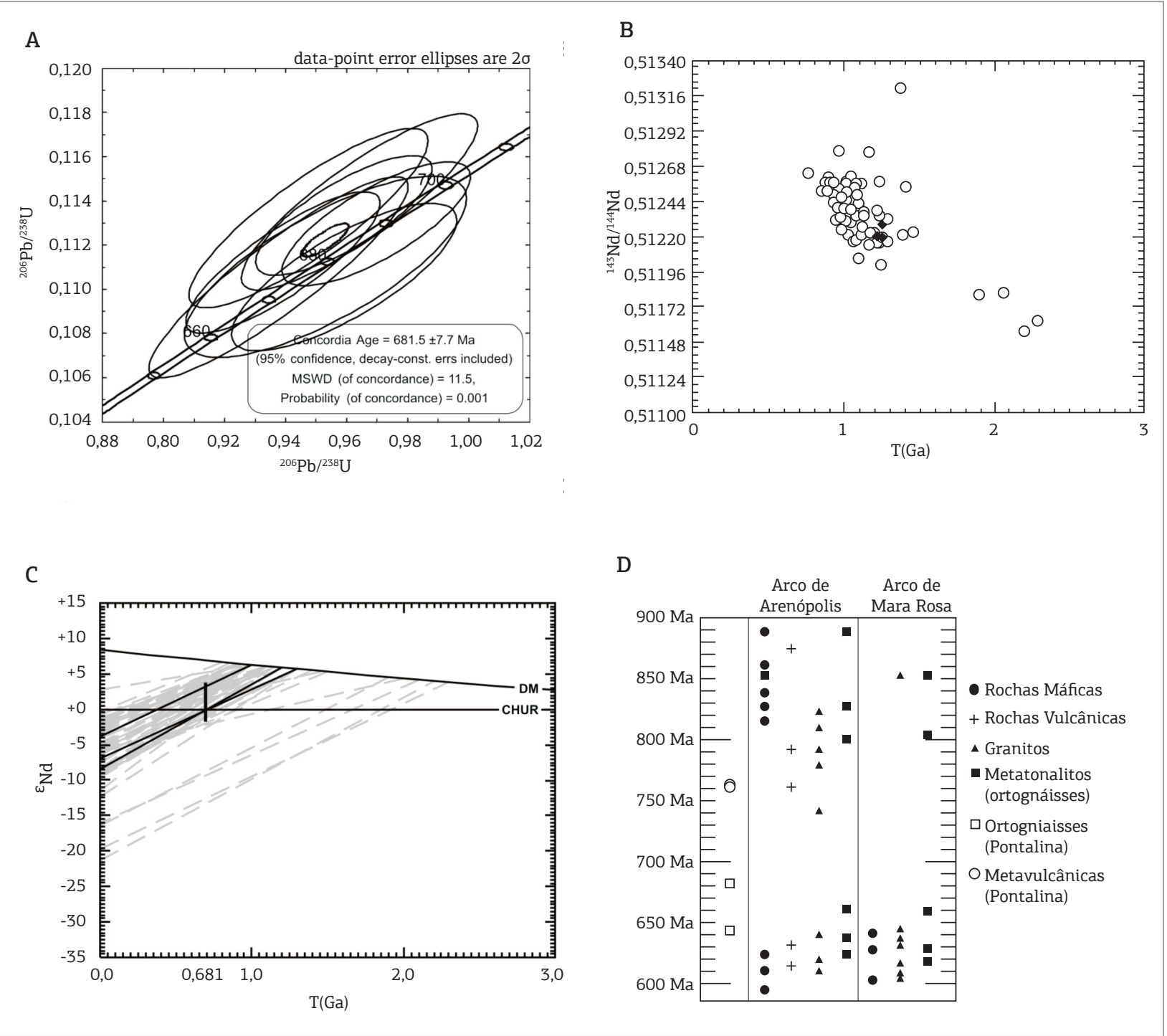

Figura 8. (A) Diagrama concórdia U-Pb, mostrando a idade de cristalização do ortognaisse Pontalina. (B) Composição isotópica ${ }^{143} \mathrm{Nd} /{ }^{144} \mathrm{Nd}$ e idades modelo do ortognaisse Pontalina e de rochas de outras regiões do Arco Magmático de Goiás. Círculos brancos: rochas de outras regiões do Arco Magmático de Goiás. Lozangos pretos: amostras do ortognáisse Pontalina. (C) Variação dos valores de $\varepsilon_{\mathrm{Nd}}$ no tempo geológico do ortognaisse Pontalina e de outras rochas do Arco Magmático de Goiás. Linhas pretas: amostras do ortognaisse Pontalina. Linhas cinza: amostras de rochas de outras regiões do Arco Magmático de Goiás. (D) Diagrama mostrando as idades de cristalização de rochas da região de Pontalina e de outras regiões do Arco Magmático de Goiás (modificado de Laux et al. 2005). Dados de Dantas et al. (2001), Fischel et al. 2001, Junges et al. (2002, 2003), Laux et al. (2002a, b, 2003a, b, 2004, 2005), Motta-Araújo \& Pimentel (2003), Pimentel \& Fuck (1992), Pimentel et al. (1991, 1997, 2000b, 2003), Piuzana et al. (2003a, b), Viana et al. (1995), Rodrigues, Gioia \& Pimentel (1999), Simões (2005).

São Francisco. As idades obitidas na região revelam idades de cristalização de $762 \pm 77$ Ma (Pimentel, Fuck \& Gioia 2000), $759 \pm 18 \mathrm{Ma}$ e de $643 \pm 3,9$ (Simôes 2005) e, a idade de $681 \mathrm{Ma}$ sugerem na região ocorreu um episódio magmático em - $760 \mathrm{Ma}$ e outro entre 690 e $640 \mathrm{Ma}$, semelhante aos ortognaisses de outras regióes do Arco Magmático de Goiás.

\section{AGRADECIMENTOS}

À Fundação de Amparo à Pesquisa do Estado de São Paulo (FAPESP), Processos no 08/50723-0 e 05/59203-1, ao Conselho Nacional de Desenvolvimento Científico e Tecnológico (CNPq), Processo no 301216/2008-8, pelo suporte financeiro concedido para a realização dessa pesquisa. 


\section{REFERÊNCIAS}

Buhn B., Pimentel M.M., Matteini M., Dantas E.L. 2009. High spatial resolution analysis of $\mathrm{Pb}$ and $\mathrm{U}$ isotopes for geochronology by laser ablation multi-collector inductively coupled plasma mass spectrometry (LA-MC-ICP-MS). Anais da Academina Brasileira de Ciências, 81(1):99-114.

Dantas E.L., Jost H., Fuck R.A., Brod J.A., Pimentel M.M., Menezes P.R. 2001. Proveniência e idade deposicional de seqüências metavulcanosedimentares da região de Santa Terezinha de Goiás, baseada em dados isotópicos Sm-Nd e U-Pb em monocristal de zircão. Revista Brasileira de Geociências, 31(3):329-334

De La Roche H., Leterrier J., Grandclaude P., Marchal M. 1980. A classification of volcanic and plutonic rocks using R1R2 - diagram and major-element analyses - ITS relationships with current nomenclature. Chemical Geology, 48:43-55.

Drake Jr. A.A. 1980. The Serra de Caldas window. U.S. Geological Survey Professional Paper, 1119-A, B. Washington, United States Government Printing Office. p.1B-19B.

De Paolo D.J. 1981. A neodymium and strontium isotopic study of the Mesozoic calc-alkaline granitic batholiths of the Sierra Nevada and Peninsular Ranges, California. Journal of Geophysical Research, 86:10470-10488.

Fischel D.P., Pimentel M.M., Fuck R.A., Armstrong R. 2001. U-Pb SHIRIMP and Sm-Nd geochronology of the Silvânia Volcanics and Jurubatuba Granite: Juvenile Paleoproterozoic crust in the basement of Neoproterozoic Brasília Belt Goiás, central Brazil. Anais da Academia Brasileira de Ciências, 73(3):445-460.

Fuck R.A. 1990. Dobramentos neoproterozóicos da margem Ocidental do Cráton do São Francisco: revisão. In: SBG, Congresso Brasileiro de Geologia, 36, Boletim Resumos, p. 288-289.

Fuck R.A., Pimentel M.M., D’el Rey Silva, L. J. H. 1994. Compartimentação tectônica na porção oriental da Província Tocantins. In: SBG, Congresso Brasileiro de Geologia, 38, Boletim Resumos Expandidos, 1:215-216

Gioia S.M.C.I., Pimentel M.M. 2000. The Sm-Nd isotopic method in the Geochronology Laboratory of the University of Brasília. Anais da Academia Brasileira de Ciências, 72:219-245.

Irvine T.N. \& Barajar W.R.A. 1971. A guide to the chemical classification of the common volcanic rocks. Canadian Journal of Earth Sciences, 8:523-548.

Junges S.L., Dantas E.L., Pimentel M.M., Laux J.H. 2002. Idades U-Pb de granitos sin- a tardi-tectônicos do Arco de Mara Rosa, Goiás. In: SBGNúcleo Nordeste, Congresso Brasileiro de Geologia, 41, Resumos, p. 312.

Junges S.L., Pimentel M.M., Dantas E.L., Laux J.H. 2003. New ID-TIMS $\mathrm{U}-\mathrm{Pb}$ ages in the western portion of the Mara Rosa Arc: Two hundred million years of arc building. In: South American Symposium on the Isotope Geology, Short Papers 1, 4:198-201.

Lacerda Filho J.V., Rezende A., Silva A. 1999. Programa de Levantamentos Geológicos Básicos do Brasil - Geologia e Recursos Minerais do Estado de Goiás e Distrito Federal. Goiânia: CPRM, METAGO, UnB, 1999, 2a ed. 184 p.

Laux J.H., Pimentel M.M., Dantas E.L., Armstrong R., Armele A. 2002a. O Arco Magmático de Goiás na região de Anicuns: Novos dados Sm-Nd e U-Pb. In: SBG-Núcleo Nordeste, Congresso Brasileiro de Geologia, 41, Resumos, p. 496

Laux J.H., Pimentel M.M., Dantas E.L., Armstrong R., Armele A. 2002b. Idade do vulcanismo associado ao Grupo Araxá e Arco Magmático de Goiás na Região de Anicuns-GO. In: SBG-Núcleo Norte, Simpósio sobre Vulcanismo e Ambientes Associados, 2, Resumos, p. 42.
Laux J.H., Pimentel M.M., Dantas E.L., Armstrong R., Armele A. 2003a. Mafic magmatism associated with the Goiás Magmatic Arc in Anicuns-GO, central Brazil: New ID-TIMS and SHIRIMP U-Pb data. In: South American Symposium on the Isotope Geology, Short Papers 2, 4:575-578.

Laux J.H., Pimentel M.M., Dantas E.L., Armstrong R., Armele A. 2003b. New U-Pb data for orthogneisses of the Neoproterozoic Goiás Magmatic Arc, central Brazil. In: South American Symposium on the Isotope Geology, Short Papers 2, 4:579-582.

Laux J.H., Pimentel M.M., Dantas E.L., Armstrong R., Armele A., Nilson A.A. 2004. Mafic magmatism associated with the Goiás Magmatic Arc in the Anicuns region, Goiás central Brazil: Sm-Nd isotopes and new ID-TIMS and SHIRIMP U-Pb data. Journal of South American Earth Sciences, 16(7):599-614.

Laux J.H., Pimentel M.M., Dantas E.L., Armstrong R., Junges S.L. 2005. Two neoproterozoic crustal accretion events in the Brasília belt, central Brazil. Journal of South American Earth Sciences, 18:183-198

Maniar P.D. \& Picolli P.M. 1989. Tectonic discriminant of granitoids. Geological Society of American Bulletin, 101:635-643.

Marini O.J., Fuck, R.A., Danni J.C.M., Dardene M.A., Lougguércio R.O., Ramalho R. 1984. As faixas de dobramentos Brasília, Uruaçu e Paraguai-Araguaia e o Maciço Mediano de Goiás. In: Schobbenhaus C., Campos D. A., Derze G. R., Asmus H. E. (Coord.). Geologia do Brasil. Brasília: DNPM., p. 251-303.

Motta-Araújo J.G., Pimentel M.M. 2003. U-Pb ages, Sm-Nd isotopes and structural analysis of the Moiporá-Novo Brazil Shear Zone System: The limits between Neoproterozoic Goiás Magmatic Arc and the Archean Uvá Complex, Tocantins Province, central Brazil. In: South American Symposium on the Isotope Geology, Short Papers 1, 4:221-224.

Navarro G.R.B. \& Zanardo A. 2006. Dados geoquímicos e isotópicos de rochas metamáficas da região de Pontalina Goiás. Revista de Geologia (Fortaleza), 19(2):207-214.

Navarro G.R.B. \& Zanardo A. 2007a. Geoquímica de Gnaisses do Arco Magmático de Goiás na região sul do estado de Goiás. Geologia USP. Série Científica, 7(1):19-28.

Navarro G.R.B. \& Zanardo A. 2007b. Características geoquímicas de gnaisses da Unidade Metassedimentar, porção sul do Arco Magmático de Goiás, na região de Pontalina. SBGq, Congresso Brasileiro de Geoquímica, $11^{\circ}$. Resumos. (CD-ROM - 539), 4 p.

Navarro G.R.B., Zanardo A., Simões L.S.A. 2007. Rochas metamáficas associadas ao Arco Magmático de Goiás na região de Pontalina - GO. Revista Brasileira de Geociências, 37(4 - suplemento especial):18-27.

Navarro G.R.B., Zanardo A., Conceição F.T., Simões L.S.A. 2011 Evolução metamórfica e termobarometria das rochas metamáficas/ metabásicas da região de Pontalina - GO. Revista Brasileira de Geociências (no prelo).

Oliveira C.C. 1994. Programa Levantamentos Básicos do Brasil PLGB. Folha SE.22-X-B-V - Leopoldo de Bulhões Escala: 1:100.000. Goiânia: CPRM, DNPM, 1994. 151 p. (Relatório não publicado).

Pearce J.A., Harris N.B.W., Tindle A.G. 1984. Trace element discrimination diagrams for the tectonic interpretation of granitic rocks. Journal of Petrology, 25:956-983.

Pimentel M.M. \& Fuck R.A. 1991. Origin of orthogneiss and metavolcanic rock units in western Goiás: Neoproterozoic crustal accretion. Geochimica Brasiliensis, 5:133-152. 
Pimentel M.M. \& Fuck R.A. 1992. Neoproterozoic crustal accretion in central Brazil. Geology, 20:375-379.

Pimentel M.M., Heaman L., Fuck R.A. 1991. Zircon ans sphene Pb-U geochronology of Upper Proterozoic volcanic-arc rock units from southwestern Goiás, central Brazil. Journal of South American Earth Sciences, 4:329-339.

Pimentel M.M., Whitehouse M.J., Viana M.G., Fuck R.A., Machado N. 1997. The Mara Rosa arc in the Tocantins Province: Further evidence for Neoproterozoic crustal accretion in central Brasil. Precambrian Research, 81:299-310

Pimentel M.M., Fuck R.A., Jost H., Ferreira Filho C.F., Araújo S.M. 2000. The basament of the Brasilia Fold Belt and the Goiás magmatic arc. In: Cordani U.G., Thomas Filho A., Campos D.A. (coord.). Tectonic Evolution of South America. Rio de Janeiro: SBG. p.195-229.

Pimentel M.M., Fuck R.A., Gioia S.M.C.L. 2000. The neoproterozoic Goiás Magmatic Arc, central Brazil: A review and new Sm-Nd isotopic data. Revista Brasileira de Geociências, 30(2):35-39.

Pimentel M.M., Hollanda M.H.B.M., Armstrong R. 2003. SHIRIMP U-Pb and Sr-Nd isotopes of the Morro do Baú mafic intrusion: Implications for the evolution of the Arenópolis volcano-sedimentary sequence, Goiás Magmatic Arc. Anais da Academia Brasileira de Ciências, 75(3):331-339.

Pimentel M.M., Jost H., Fuck R.A. 2004. O embasamento da Faixa Brasília e o arco Magmático de Goiás. In: Mantesso-Neto V., Bartorelli A., Carneiro C. Dal Ré, Brito-Neves B.B. (Org.). Geologia do Continente Sul-Americano: evolução da obra de Fernando Flávio Marques de Almeida. São Paulo: Beca, p. 355-368.

Piuzana D., Pimentel M.M., Fuck R.A.; Armstrong R. 2003a. Neoproterozoic granulite facies metamorphism and coeval granitic magmatism in the Brasília Belt, central Brazil: regional implications of SHRIMP U-Pb and Sm-Nd data. Precambrian Research, 125:245-273.

Piuzana D., Pimentel M.M., Fuck R.A.; Armstrong R. 2003b. SHRIMP U-Pb and Sm-Nd data for the Araxá Group and associated magmatic rocks: constraints for the age of sedimentation and geodynamic context of the southern Brasília Belt, central Brazil. Precambrian Research, 125:139-160.
Richard L.R. 1995. Mineralogical and Petrological Data Processing System. MINPET for Windows. Version 2.02. Copyright 1988-1995.

Rodrigues J.B., Gioia S.M.L.C., Pimentel M.M. 1999. Geocronologia e geoquímica de ortognaisse da região de Iporá e Firminópolis: Implicações para a evolução do Arco Magmático de Goiás. Revista Brasileira de Geociências, 29(2):207-216

Seer H.J., Brod J.A., Fuck R.A., Pimentel M.M., Boaventura G.R. Dardenne M.A. 2001. Grupo Araxá em sua área tipo: um fragmento de crosta oceânica neoproterozóica na Faixa de Dobramentos Brasília. Revista Brasileira de Geociências, 31(3):385-396.

Simões L.S.A. 2005. Compartimentos Crustais do Domínio Interno da Faixa Brasília no sul do estado de Goiás. Tese (Livre Docência), Instituto de Geociências e Ciências Exatas, Universidade Estadual Paulista Júlio de Mesquita Filho, Rio Claro, SP, 104 p.

Strieder A.J. \& Nilson A.A. 1992. Melange ofiolítica nos metassedimentos Araxá de Abadiânia (GO) e implicações tectônicas regionais. Revista Brasileira de Geociências, 22(2):204-215.

Taylor S.R. \& MacLennan S.M. 1985. The continental crust: its composition and evolution. Oxford: Blackwell, 312 p.

Valeriano C.M., Dardenne M.A., Fonseca M.A., Simões L.S.A., Seer H.J. 2004. A evolução tectônica da Faixa Brasília. In: Mantesso-Neto V., Bartorelli A., Carneiro C.D.R., Brito-Neves B.B. (org.). Geologia do Continente Sul-Americano: evolução da obra de Fernando Flávio Marques de Almeida. São Paulo: Beca. p. 575-592.

Viana M.G., Pimentel M.M., Whitehouse M.J., Fuck R.A., Machado N. 1995. O arco magmático de Mara Rosa, Goiás: Geoquímica e geocronologia e suas implicações regionais. Revista Brasileira de Geociências, 25(2):111-123.

Arquivo digital disponível on-line no site www.sbgeo.org.br 